\title{
FIBER OPTIC SENSING TECHNOLOGY FOR MEASURING IN-CYLINDER PRESSURE IN AUTOMOTIVE ENGINES
}

\author{
A Dissertation \\ by \\ TAEHAN BAE \\ Submitted to the Office of Graduate Studies of \\ Texas A\&M University \\ in partial fulfillment of the requirements for the degree of \\ DOCTOR OF PHILOSOPHY
}

August 2006

Major Subject: Electrical Engineering 


\title{
FIBER OPTIC SENSING TECHNOLOGY FOR MEASURING IN-CYLINDER PRESSURE IN AUTOMOTIVE ENGINES
}

\author{
A Dissertation \\ by \\ TAEHAN BAE \\ Submitted to the Office of Graduate Studies of \\ Texas A\&M University \\ in partial fulfillment of the requirements for the degree of \\ DOCTOR OF PHILOSOPHY
}

\begin{abstract}
Approved by:
Co-Chairs of Committee, Ohannes Eknoyan

Henry F. Taylor

Committee Members, Chin B. Su

Jerald Caton

Head of Department, Costas N. Georghiades
\end{abstract}

August 2006

Major Subject: Electrical Engineering 


\begin{abstract}
Fiber Optic Sensing Technology for Measuring

In-Cylinder Pressure in Automotive Engines. (August 2006)

Taehan Bae, B.S., University of Seoul, Seoul, Korea;

M.S., Texas A\&M University

Co-Chairs of Advisory Committee: Dr. Ohannes Eknoyan

Dr. Henry F. Taylor
\end{abstract}

A new fiber optic sensing technology for measuring in-cylinder pressure in automotive engines was investigated. The optic sensing element consists of two mirrors in an in-line single mode fiber that are separated by some distance. To withstand the harsh conditions inside an engine, the Fiber Fabry-Perot Interferometer (FFPI) element was coated with gold and copper. The metal-protected fiber sensor was embedded into a small cut in the metal casing of the spark plug. At first, the sensing element was dipped in liquid gold and cured. Then the gold-coated fiber sensor was electroplated with copper. Finally, the metal-coated fiber sensor was embedded in the spark plug.

The spark-plug-embedded FFPI sensor was monitored using a signal conditioning unit. Field tests were carried out in a 3-cylinder automotive engine with a piezoelectric pressure sensor as a reference transducer up to about $3500 \mathrm{rpm}$. The fiber optic sensor data generally matched those measured by the piezoelectric reference sensor. 
The use of a Vertical Cavity Surface Emitting Laser (VCSEL) diode as a light source in an FFPI optic sensor system was investigated. Reflected light from the FFPI sensing element was used to measure the optical path difference.

With a $1550 \mathrm{~nm}$ VCSEL as the light source in a $12 \mathrm{~mm}$ cavity length Fiber Fabry-Perot Interferometer, spectral characteristics were examined to determine the proper combination of dc bias current, modulation current amplitude and modulation frequency. Single VCSEL operation and regular fringe patterns were achieved.

The laser tuning was $-41.2 \mathrm{GHz} / \mathrm{mA}$ and was determined from measurements of the shift in the spectral peak of the VCSEL diode output as a function of dc bias current. By testing the fringe movement as the FFPI sensor was heated, the temperature tuning coefficient for the optical length was determined to be $11 \times 10^{-6}{ }^{\circ} \mathrm{C}$.

The results of these experiments indicate that the use of VCSEL diode as a light source for the FFPI sensor offers a viable alternative to the use of Distributed Feedback (DFB) laser diodes for monitoring at a lower bias current and modulating current amplitude. 
To My Parents

And

In Memory Of Henry Fuller Taylor III, Ph.D. 


\section{ACKNOWLEDGMENTS}

First of all, I cannot thank enough Dr. Henry F. Taylor, the former chairman of my advisory committee, who sincerely guided me through the entire research project for seven years. God bless him. Also, I am greatly thankful to Dr. Ohannes Eknoyan, who in lieu of Dr. Taylor, assumed responsibility as my academic advisor.

I would also like to thank Dr. Chin Su and Dr. Jerald Caton for serving as members of my graduate committee and for providing me with suggestions and comments on my work. I especially would like to thank Kyungwoo Lee for discussions and advice.

My appreciation is also extended to Robert Atkins for his active cooperation and kindness. I also thank Jim Gardner, who is a staff member in our lab, for sharing his expertise and helping in this research.

Special thanks go to my parents, Mr. Jinkook and Mrs. Soonpil Hong, for their love and support. I express my thanks also to my parents-in-law, Mr. K.S. Park and Mrs. M.Y. Lee. I would like to express my appreciation to my sisters, Kyunghee, Soojung, Jihyun and Soohyun, to my brother-in-law, S.H. Yoon, H.K. Shim and B. K.Lee and to everyone else in my family.

I would like to share this day and everyday with my lovely wife, Jihyun Park for her love, patience and sacrifice during my study here. 


\section{TABLE OF CONTENTS}

Page

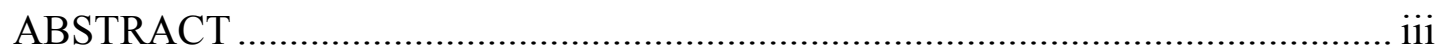

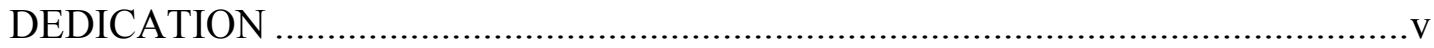

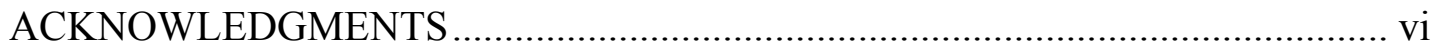

TABLE OF CONTENTS .......................................................................... vii

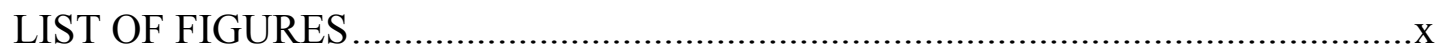

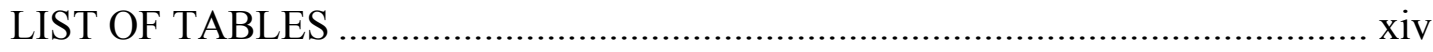

CHAPTER

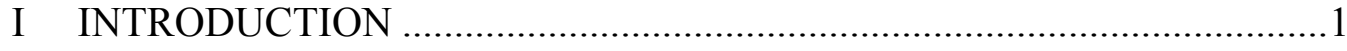

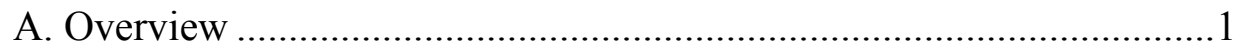

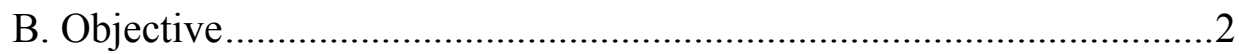

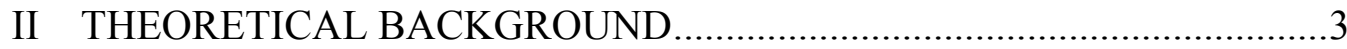

A. Fiber Fabry-Perot Interferometer (FFPI) .....................................3

B. Advantage of the Fiber Optic Sensor .............................................5

C. Vertical Cavity Surface Emitting Laser (VCSEL) Diode ...................6

III FFPI SENSOR FABRICATION ....................................................... 9

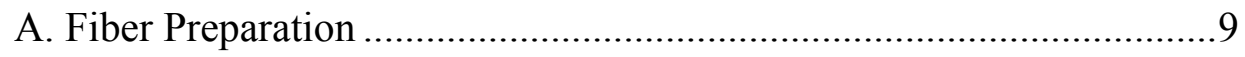

B. Fiber End Coating .........................................................................10

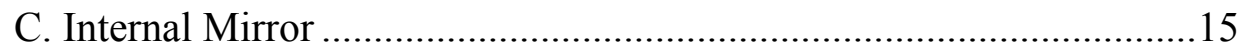


CHAPTER $\quad$ Page

IV EXPERIMENTAL PROCEDURE AND FIELD TEST RESULTS...........20

A. Spark Plug Mounted Fiber Optic Pressure Sensor Fabrication ..........20

1. The Gold Coating........................................................................... 20

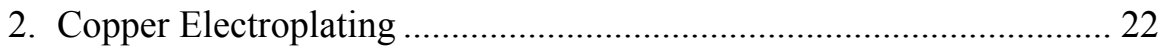

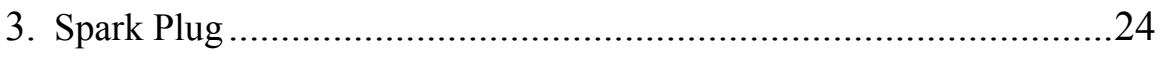

B. Field Test and Results .......................................................27

1. Deadweight Calibration................................................................... 27

2. Test Configuration............................................................ 30

3. Test Result ...................................................................... 32

V EXPERIMENTAL PROCEDURE AND TEST FOR VCSEL ....................36

A. Experimental Investigation of VCSEL..........................................36

B. Dependence of Fringe Patterns on VCSEL Spectral Characteristics .41

C. Operation of FFPI Sensor with VCSEL at High Modulation Frequency and Modulation Depth.................................................44

D. Dependence of VCSEL Frequency on Drive Current ......................46

E. Dependence of FFPI Sensor Fringe Pattern on Temperature .............48

F. Discussion and Analysis of Results ...........................................50

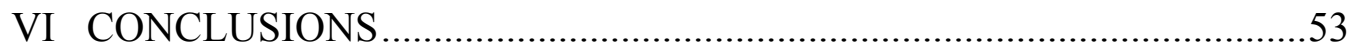

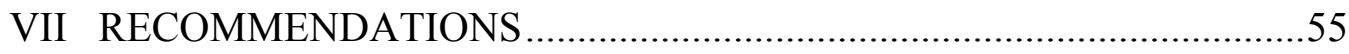

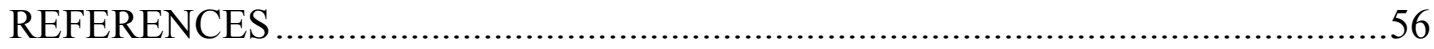




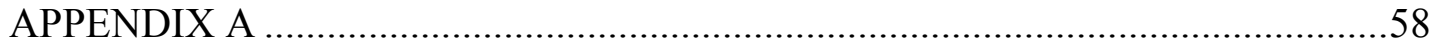

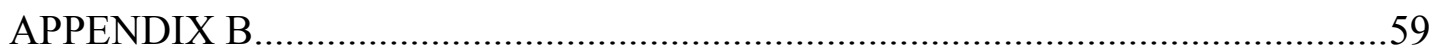

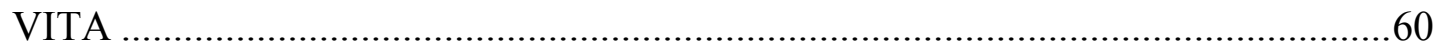




\section{LIST OF FIGURES}

FIGURE Page

1 Fiber Fabry-Perot Interferometer .............................................................

2 Vertical Cavity Surface Emitting Laser (VCSEL) .......................................

3 Current vs power of VERTILAS VCL1550 VCSEL .................................... 8

4 Spectrum of single mode VCL1550 VCSEL at 1.5mA dc bias current........8

5 Configuration of the Fiber Fabry-Perot Interferometer.................................11

6 Dependence of internal mirror reflectance on $\mathrm{TiO}_{2}$ film thickness at a

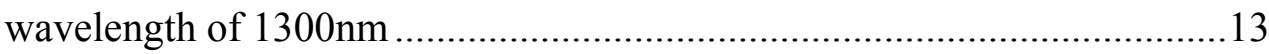

7 Dependence of internal mirror reflectance on $\mathrm{TiO}_{2}$ film thickness at a

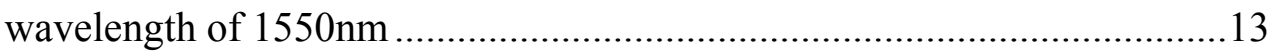

8 First maximum in reflectance as a function of $\mathrm{TiO}_{2}$ film thickness at a

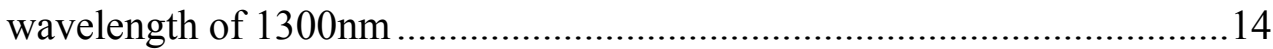

9 First maximum in reflectance as a function of $\mathrm{TiO}_{2}$ film thickness at a

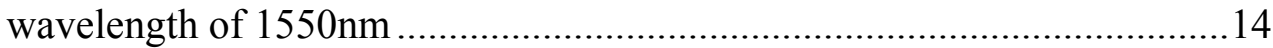

10 Basic configuration of electric arc fusion splice .......................................15

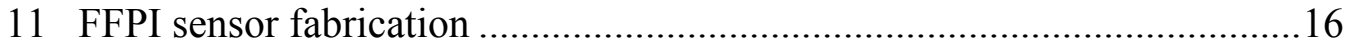

12 The setup for fabricating the FFPI sensor .................................................18

13 Optical signal reflected from the sensor......................................................19

14 The setup for monitoring the reflectance of the gold-coated fiber...............21 


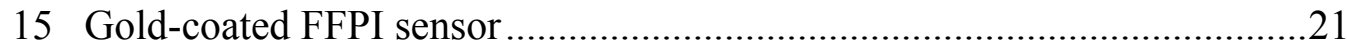

16 The setup for copper electroplating of a gold-coated fiber ......................23

17 The gold-coated and copper electroplated FFPI sensor ..........................24

18 Configuration for spark plug mounted fiber optic sensor .......................26

19 Connectorized fiber sensor assembly for use in automotive engine ..........27

20 Deadweight test setup for calibration............................................28

21 Setup for measure in-cylinder pressure of a 3-cylinder automotive engine

22 In-cylinder pressure comparison between a spark-plug-mounted optic sensor and a piezoelectric sensor in around 1200rpm

23 In-cylinder pressure comparison between a spark-plug-mounted optic sensor and a piezoelectric sensor in around 1500rpm

24 In-cylinder pressure comparison between a spark-plug-mounted optic sensor and a piezoelectric sensor in around 2000rpm

25 In-cylinder pressure comparison between a spark-plug-mounted optic sensor and a piezoelectric sensor in around 2500rpm

26 In-cylinder pressure comparison between a spark-plug-mounted optic sensor and a piezoelectric sensor in around 3000rpm

27 In-cylinder pressure comparison between a spark-plug-mounted optic sensor and a piezoelectric sensor in around 3500rpm 
28 In-cylinder pressure comparison between two spark-plug-mounted optic sensors and a piezoelectric sensor in around 2500rpm

29 Experimental setup for VCSEL

30 Temporal dependence of sensor output power using VCL1550 VCSEL light source for saw-tooth modulating waveforms at different bias current levels. In each case the modulation peak to peak amplitude is $0.6 \mathrm{~mA}$, the horizontal scale is $200 \mu \mathrm{s} / \mathrm{div}$, and modulation frequency is $1 \mathrm{kHz}$. In each frame the upper trace is the modulation current and the lower trace is the sensor response

31 Temporal dependence of sensor output power using VCL1550 VCSEL light source for saw-tooth modulating waveforms at different modulation current levels. In each case the dc bias current is $3.0 \mathrm{~mA}$, the horizontal scale is $200 \mu \mathrm{s} / \mathrm{div}$, and modulation frequency is $1 \mathrm{kHz}$. In each frame the upper trace is the modulation current and the lower trace is the sensor response

32 Temporal dependence of sensor output power using VCL1550 VCSEL light source for saw-tooth modulating waveforms at different modulation frequency. In each case the dc bias current is $2.4 \mathrm{~mA}$ and the modulation peak to peak amplitude is $0.8 \mathrm{~mA}$. In each frame the upper trace is the modulation current and the lower trace is the sensor response 
FIGURE Page

33 Operating regions for FFPI sensor with a VCSEL ...............................42

34 The fringe pattern of FFPI sensor at each point indicated in Fig. 33 .........43

35 Fringe pattern of FFPI sensor with VCSEL modulation frequency $10 \mathrm{kHz}, 20 \mathrm{kHz}, 50 \mathrm{kHz}$ and $100 \mathrm{kHz}$ with a horizontal scale of $20 \mu \mathrm{s} / \mathrm{div}, 10 \mu \mathrm{s} / \mathrm{div}, 5 \mu \mathrm{s} / \mathrm{div}$ and $2 \mu \mathrm{s} / \mathrm{div}$ respectively. Bias current $3.0 \mathrm{~mA}$ and modulation current is $0.8 \mathrm{~mA}$............................................44

36 Spectrum of de biased VCL1550 VCSEL .............................................46

37 Spectrum of VCL1550 VCSEL with de bias current when a saw-tooth modulation current $(0.6 \mathrm{~mA})$ is applied. Modulation frequency is $100 \mathrm{kHz}$

38 Dependence of fringe pattern on temperature when the sensor is monitored with a $1550 \mathrm{~nm}$ VCSEL with temperature range $142^{\circ} \mathrm{C}$ to $154^{\circ} \mathrm{C}$ with $2.7 \mathrm{~mA}$ bias current and $0.8 \mathrm{~mA}$ modulation current 


\section{LIST OF TABLES}

TABLE

Page

I The calibration constant and sensitivity 


\section{CHAPTER I}

\section{INTRODUCTION}

\section{A. Overview}

In 1997, 56 million motor vehicles were produced worldwide and 709 million were registered. Compared to this, in 2005 approximately 65 million vehicles were manufactured and the number of registered motor vehicles is currently estimated to be about 800 million. [1]. As the number of vehicles continues to increase, it is evident that a more effective and economical way to reduce energy consumption and harmful emissions from automotive and truck engines is urgently needed. To achieve such a result, optimized engine control is indispensable. In-cylinder pressure is widely thought to be the most important parameter for engine control systems [2]. If this pressure information is properly employed, engine performance can be optimized to minimize both emissions and fuel consumption. Because of the high temperature and high pressure experienced in automotive engines, conventional pressure sensors are not suitable for operation in such an environment for long time periods.

The journal model is IEEE Journal of Lightwave Technology. 
Fiber optic Fabry-Perot Interferometers (FFPIs) have been investigated for sensing in engines for over a decade. Since the FFPI sensor was initially researched at Texas A\&M University in 1987 [3-9], FFPI pressure sensors have shown an unprecedented reliability in large stationary natural gas engines and diesel engines. However, these earlier sensor designs required a separate port in the cylinder head for mounting the sensor, and no such port is available in automotive engines. A new form of packaging is needed for the FFPI pressure sensor to be useful in automobiles.

In the previous work on engine pressure sensing, edge emitting distributed feedback (DFB) laser diodes with a wavelength near $1300 \mathrm{~nm}$ were used for monitoring the fiber optic sensors. However, these DFB laser diodes are much too expensive for automotive application. A new type of light source, the vertical cavity surface emitting laser (VCSEL) diode, has recently emerged as a potentially low cost alternative to the DFB laser in automotive sensing applications.

\section{B. Objective}

The purpose of this research is to investigate a new technology for use in the practical measurement of pressure in automotive engines; in particular, to show that FFPI pressure sensors packaged in a spark plug can give accurate measurements of incylinder pressure, and to explore the use of a single mode 1550nm VCSEL diode in the monitoring of FFPI sensors. 


\section{CHAPTER II}

\section{THEORETICAL BACKGROUND}

\section{A. Fiber Fabry-Perot Interferometer (FFPI)}

An FFPI is formed by two mirrors in a single mode optical fiber, separated by a distance $\mathrm{L}$ [Fig. 1]. The reflectance $\mathrm{R}_{\mathrm{FP}}$ can be expressed as

$$
R_{F P}=\frac{P_{r}}{P_{i}}=R_{1}+R_{2}+2 \sqrt{R_{1} R_{2}} \cos \phi
$$

with $\mathrm{P}_{\mathrm{r}}$ the reflected optical power, $\mathrm{P}_{\mathrm{i}}$ the incident optical power, $\phi$ the round-trip optical phase shift, and mirror reflectances $\mathrm{R}_{1}, \mathrm{R}_{2}<<1$.

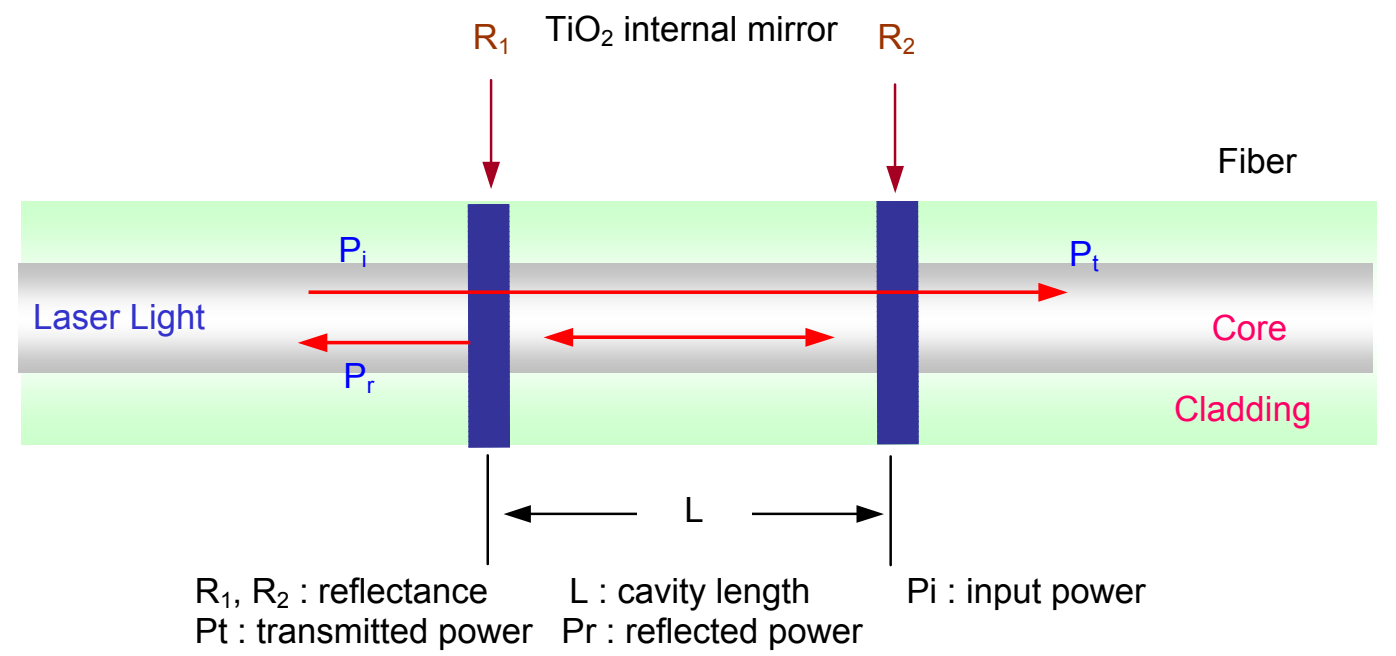

Fig. 1 Fiber Fabry-Perot Interferometer. 
If the reflectance of $\mathrm{R}_{1}$ and $\mathrm{R}_{2}$ are the same, with $\mathrm{R}_{1}, \mathrm{R}_{2}<<1, \mathrm{R}_{\mathrm{FP}}$ can be expressed as

$$
R_{F P}=\frac{P_{r}}{P_{i}}=2 R(1+\cos \phi)
$$

with $\mathrm{R}$ the reflectance of the mirror, $\phi$ the round-trip phase shift of the light in the interferometer, given by

$$
\phi=\frac{4 \pi v n L}{c}=\frac{4 \pi n L}{\lambda}
$$

with L the cavity length of the interferometer, $v$ the optical frequency of the laser light, $\mathrm{n}$ the refractive index of the fiber mode, $\mathrm{c}$ the free-space speed of light, and $\lambda$ the free space wavelength of the light source.

The variation of phase $\phi$ can also be expressed as the sum of variations of length $\Delta \mathrm{L}$, frequency $\Delta \mathrm{v}$ and temperature $\Delta \mathrm{T}$.

$$
\phi=\phi_{0}+\Delta \phi_{L}+\Delta \phi_{v}+\Delta \phi_{T}
$$

with

$$
\begin{gathered}
\Delta \phi_{L}=\frac{4 \pi n}{\lambda} \Delta L \\
\Delta \phi_{v}=\frac{4 \pi L}{c}\left(n+v \frac{d n}{d v}\right) \Delta v
\end{gathered}
$$




$$
\Delta \phi_{T}=\frac{4 \pi}{\lambda}\left(L \frac{d v}{d T}+n \frac{d L}{d T}\right) \Delta T
$$

where $\phi_{0}$ is the initial round trip phase shift.

The sensitivity of FFPI sensor can be measured in two ways. If the round trip

phase shift is $2 N \pi \pm \frac{\pi}{2}(\mathrm{~N}=$ integer $)$, the FFPI can have a maximum sensitivity at the quadrature point. Whereas, if $\phi$ is $2 N \pi \pm \pi(\mathrm{N}=$ integer $)$, the sensitivity is zero.

Thus, by monitoring the reflected power several factors such as temperature, pressure, and / or strain physical perturbations which change the optical path length $\mathrm{nL}$ can be sensed.

\section{B. Advantage of the Fiber Optic Sensor}

Fiber optic sensors have become one of the common applications in the sensor market. Because of their exclusive advantages, FFPI sensor is recognized as a strong candidate in various areas of sensing physical parameters such as temperature, pressure, strain, rotation and chemical content.

Their significant advantages also include: (1) higher sensitivity and faster

response than conventional sensors, (2) geometrical versatility, (3) immunity to electromagnetic interference, (4) sensing regions can be remotely located and (5) operate well at high temperature. It has been tested over temperatures ranging from - 
$200^{\circ} \mathrm{C}$ up to $1050{ }^{\circ} \mathrm{C}[10]$. Because of their compactness, fiber sensors can be adapted in any small place, which facilitates mounting it in a spark plug.

The piezoelectric combustion pressure sensors have been used for a long time in most pressure sensing systems. Those conventional piezoelectric pressure sensors, which are also adopted as a reference sensor in this research, are not cost effective. They need circulating water-cooling system and frequent calibration. The FFPI sensor does not need cooling and it can be operated for many years without recalibration.

\section{Vertical Cavity Surface Emitting Laser (VCSEL) Diode}

The vertical cavity surface emitting laser (VCSEL) diode, illustrated in Fig. 2, is a semiconductor laser diode that emits light in a cylindrical beam vertically from the surface of the substrate, unlike edge emitting semiconductor lasers such as the DFB laser diode [11].

Developed for use in high-speed optical communication networks, the VCSEL is less expensive to manufacture in quantity, easier to test, and more efficient in converting electrical power into optical power than other semiconductor lasers. Their low threshold currents make them possible to implement in high-density arrays. Most importantly for automotive sensing applications, VCSELs are much less expensive than DFB lasers. However, until recently the only commercially available VCSELs 
have been multimode, while single mode lasers are needed for the monitoring of FFPI sensors [12].

In this research, a VERTILAS VCSEL diode VCL1550 is used. This laser diode emits in the $1550 \mathrm{~nm}$ wavelength regime with a threshold current of about 1.09 $1.15 \mathrm{~mA}$, as indicated in the dependence of output power on current shown in Fig. 3. The spectrum of this single mode VCSEL at a dc bias of $1.5 \mathrm{~mA}$ is shown in Fig. 4.

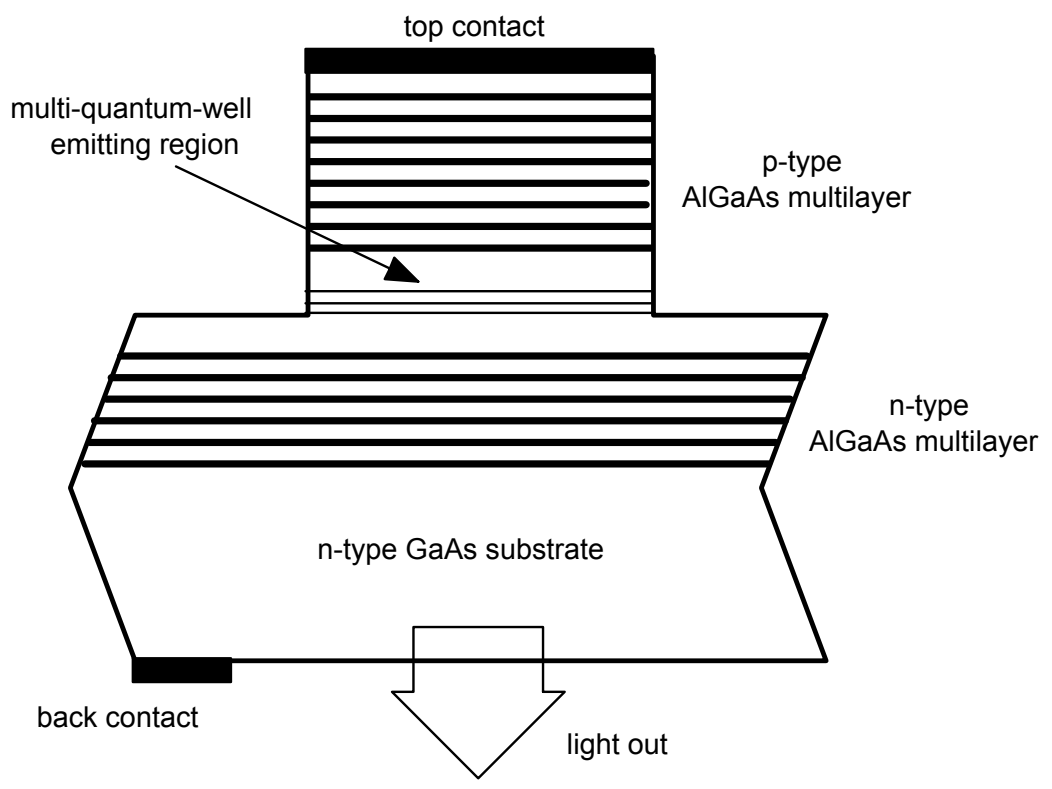

Fig. 2 Vertical Cavity Surface Emitting Laser (VCSEL). 


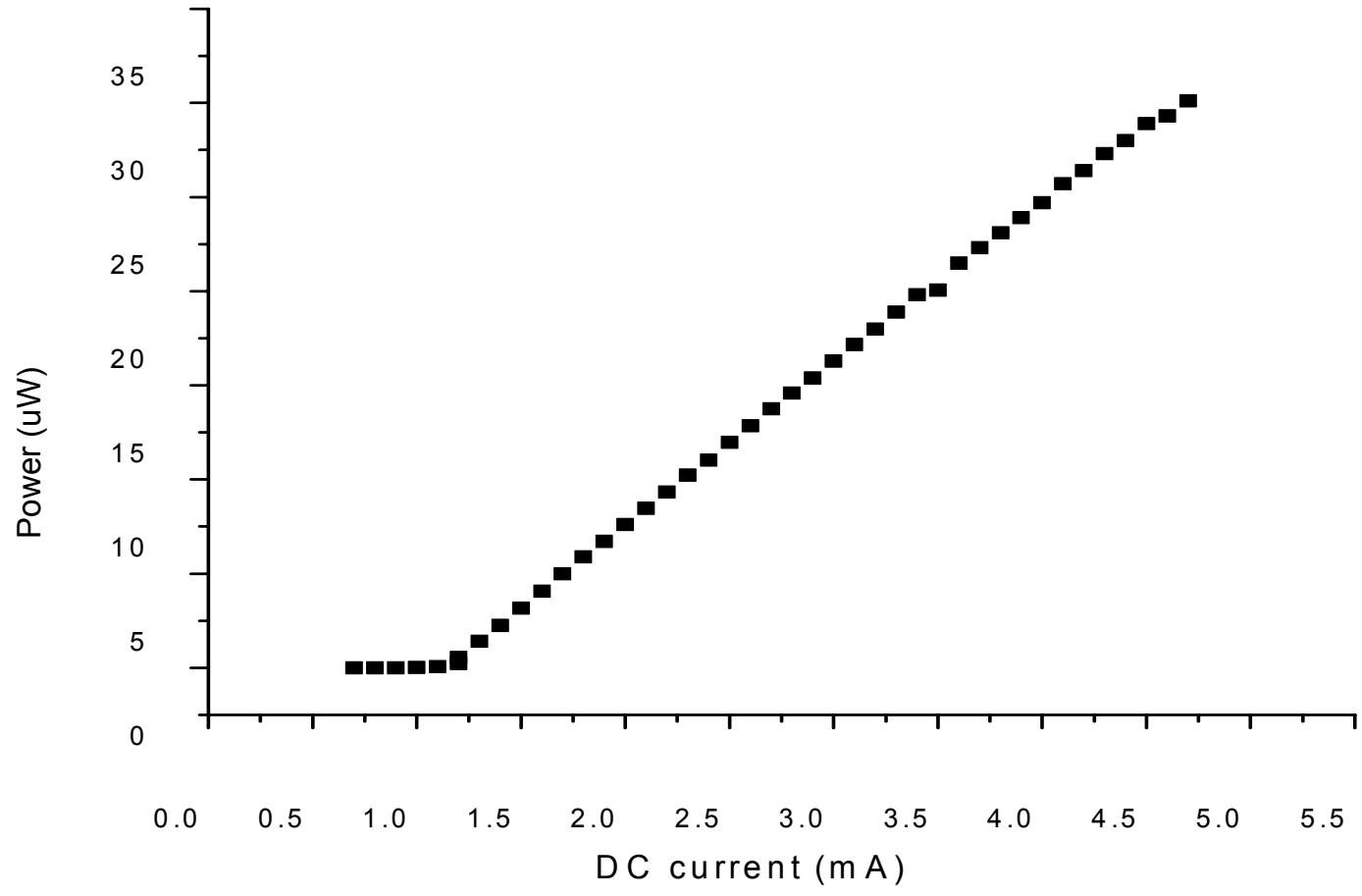

Fig. 3 Current vs power of VERTILAS VCL1550 VCSEL.

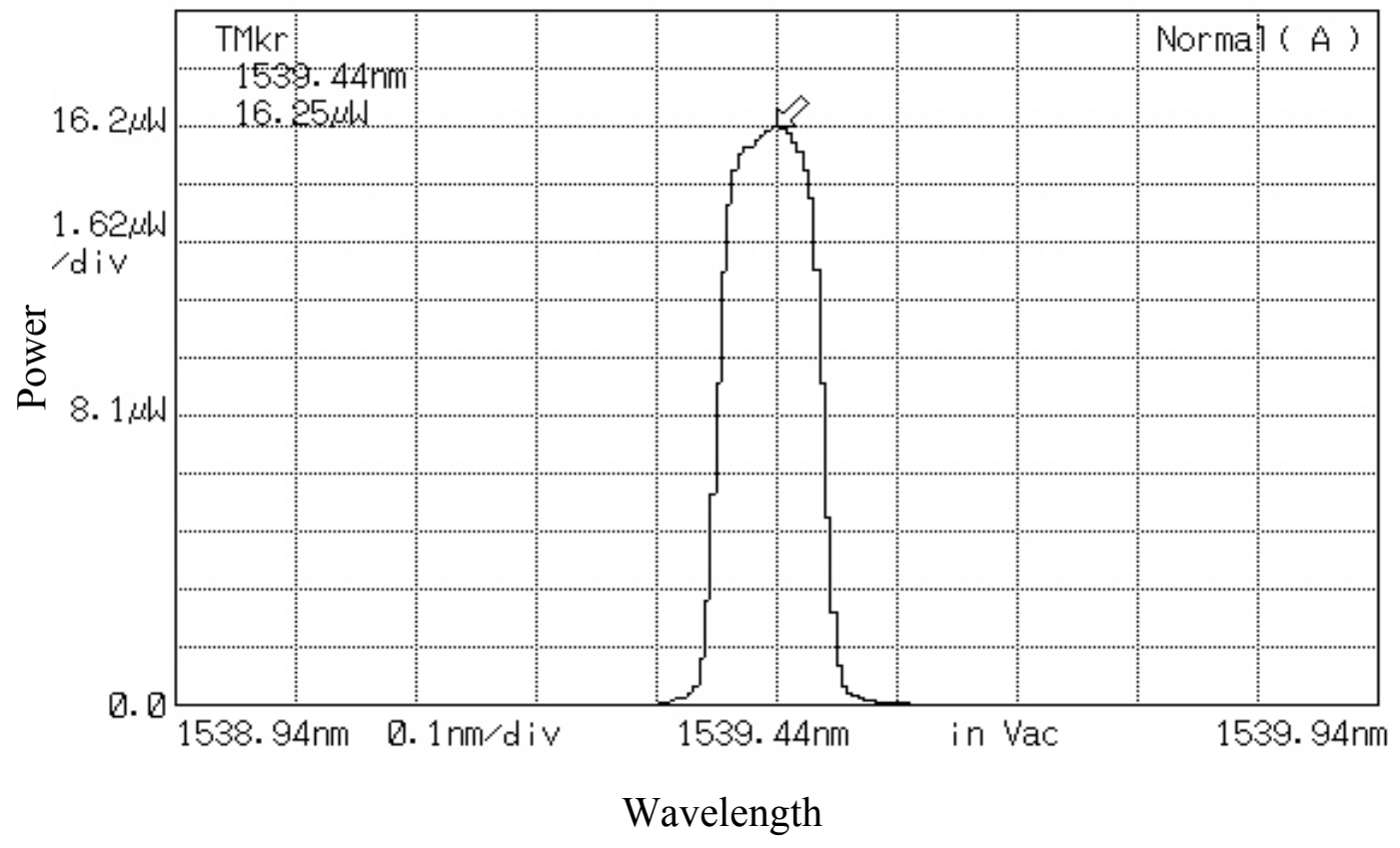

Fig. 4 Spectrum of single mode VCL1550 VCSEL at $1.5 \mathrm{~mA}$ dc bias current 


\section{CHAPTER III}

\section{FFPI SENSOR FABRICATION}

In this research, the sensing element is in-line Fiber Fabry-Perot Interferometer (FFPI) fabricated in a single-mode fused silica fiber. These sensors were designed to operate and test in the wavelength $1300 \mathrm{~nm}$ range of DFB laser and the wavelength $1550 \mathrm{~nm}$ range of VCSEL diode.

\section{A. Fiber Preparation}

Fiber preparation for making sensor starts with the strip of the polymer buffer coating from the single mode fiber. Then, the end of the fiber is shaped flat by cleaving or polishing.

Even though, polishing is generally more appropriate method for getting a desired result, it requires much more time to prepare compared to the cleaving method. Cleaving, on the other hand, has a possibility of some mechanical damage, but is more time effective to produce.

To make a good sensor, the end of the fiber needs to be cleaned and checked to ensure that its end face is perpendicular to its axis. The condition of an end surface of the fiber is one of the most critical conditions to produce an internal mirror. 


\section{B. Fiber End Coating}

A thin film of $\mathrm{TiO}_{2}$ is deposited on the fiber end by a magnetron sputtering machine. Because of the high refractive index over visible and infrared spectral ranges and strong molecular bonding on glass based materials, $\mathrm{TiO}_{2}$ material is chosen for coating the end of fiber [13]. With a mixture of argon and oxygen, the magnetron sputtering machine deposits the titanium and oxygen atoms on the cleaved fiber end until a desired film thickness is reached.

For the $1300 \mathrm{~nm}$ wavelength DFB laser and 1550nm wavelength VCSEL diodes that were used in this research, the proper $\mathrm{TiO}_{2}$ coating thickness corresponds to that for maximum reflectance after fusion splicing. For connecting the two fibers, arc fusion splicing is typically used. The more splicing is applied, the stronger the bonding strength becomes. In producing internal fiber mirrors, often short arc time and low current are used than in normal splicing. This makes the bonding strength to be weak. Therefore, repeated short arc times are used to ensure the bonding strength. Specifically, in case of the engine pressure sensor, the bonding strength of an internal mirror is extremely important. The coating thickness depends on deposition time.

It is possible to calculate the thickness of the internal mirror theoretically. This is shown as Fig. 5, with $\mathrm{n}_{1}, \mathrm{n}_{3}$ the refractive index of a single mode fiber core, $\mathrm{n}_{2}$ the refractive index of a $\mathrm{TiO}_{2}$ and the thickness of the $\mathrm{TiO}_{2}$ thin film. 
Sinale Mode Fiber

(a)

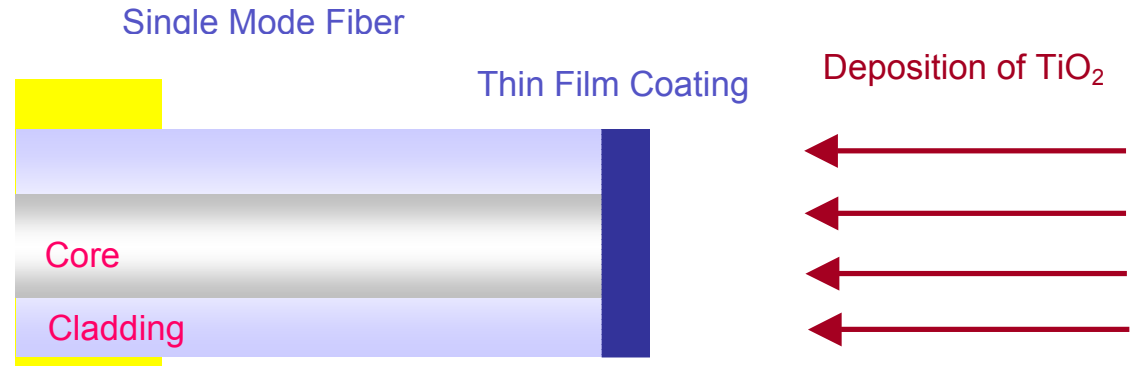

(b)

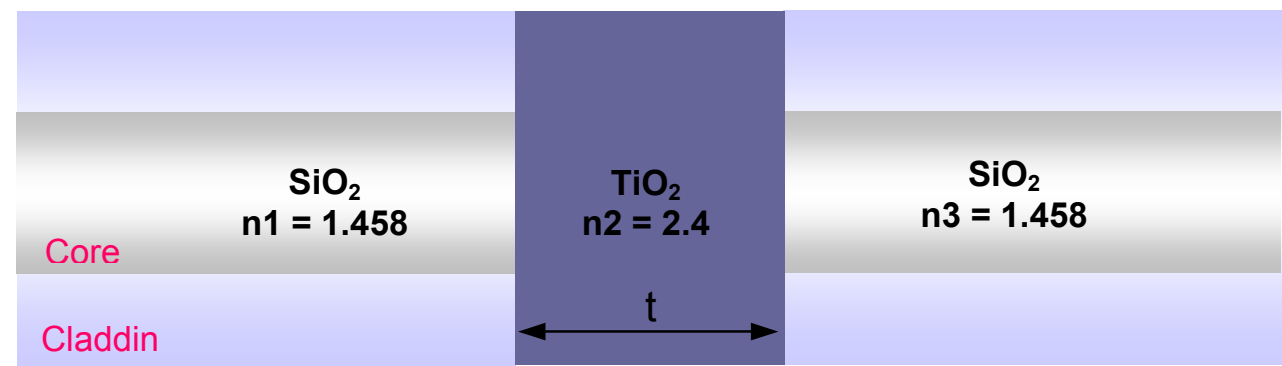

Fig. 5 Configuration of the Fiber Fabry-Perot Interferometer.

(a) Deposition of thin $\mathrm{TiO}_{2}$ film using a magnetron sputtering machine.

(b) $\mathrm{TiO}_{2}$ thin film as a internal mirror between single mode fiber. 
Theoretically, the reflectance $\mathrm{R}$ of the internal mirror is calculated, from

$$
R=A_{12}{ }^{2}+A_{23}{ }^{2}+2 A_{12} A_{23} \cos \left(\frac{4 \pi n_{2} t}{\lambda}\right)
$$

where

$$
A_{12}=\frac{n_{1}-n_{2}}{n_{1}+n_{2}}, A_{23}=\frac{n_{2}-n_{3}}{n_{2}+n_{3}}
$$

and

$$
\phi=\frac{4 \pi n_{2} t}{\lambda}
$$

Using $\mathrm{n}_{1}=\mathrm{n}_{3}=1.458, \mathrm{n}_{2}=2.4$ and $\lambda=1.3 \mu \mathrm{m}$ or $\lambda=1.55 \mu \mathrm{m}$, the internal mirror reflectance variation with the thickness of $\mathrm{TiO}_{2}$ film can be determined, and is shown in Fig. 6 and Fig. 7. Maximum reflectance is predicted for a film thickness of about $1350 \AA$ at $\lambda=1300 \mathrm{~nm}$, and about $1610 \AA$ at $\lambda=1550 \mathrm{~nm}$. The predicted maximum reflectance is about 0.24 in both cases [Fig. 8,9]. 


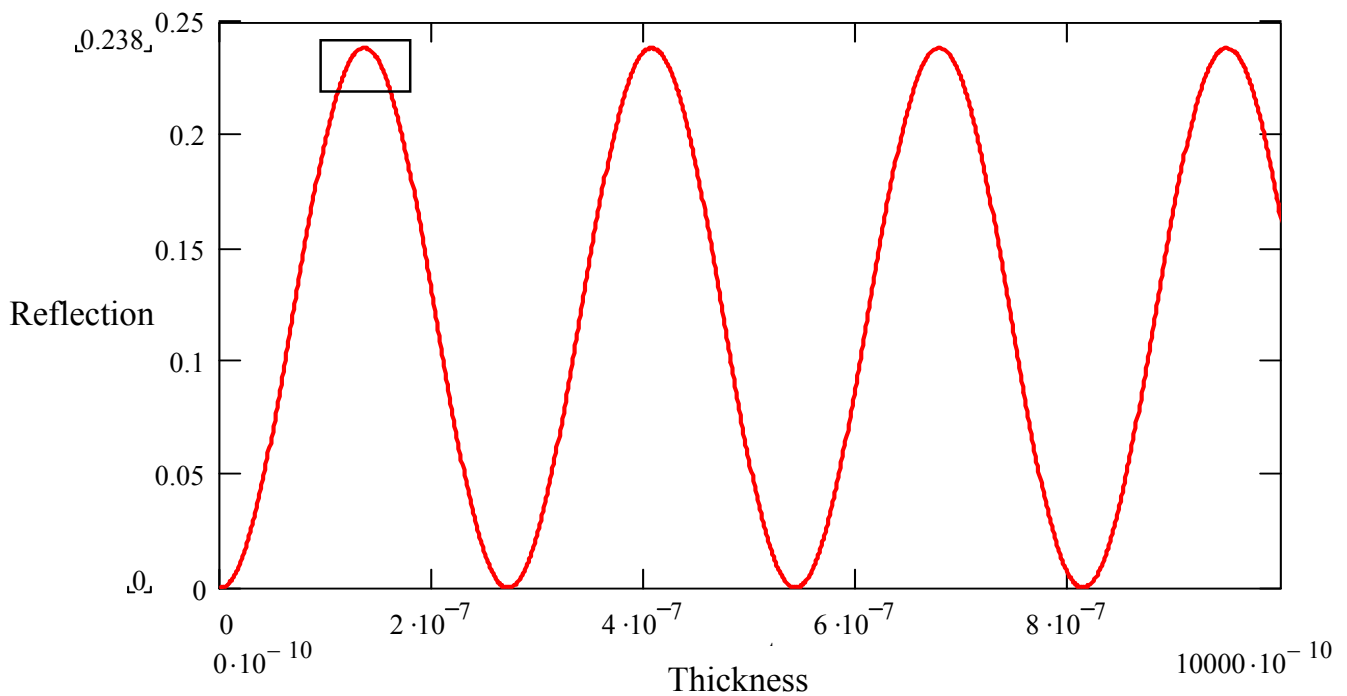

Fig. 6 Dependence of internal mirror reflectance on $\mathrm{TiO}_{2}$ film thickness at a wavelength of $1300 \mathrm{~nm}$.

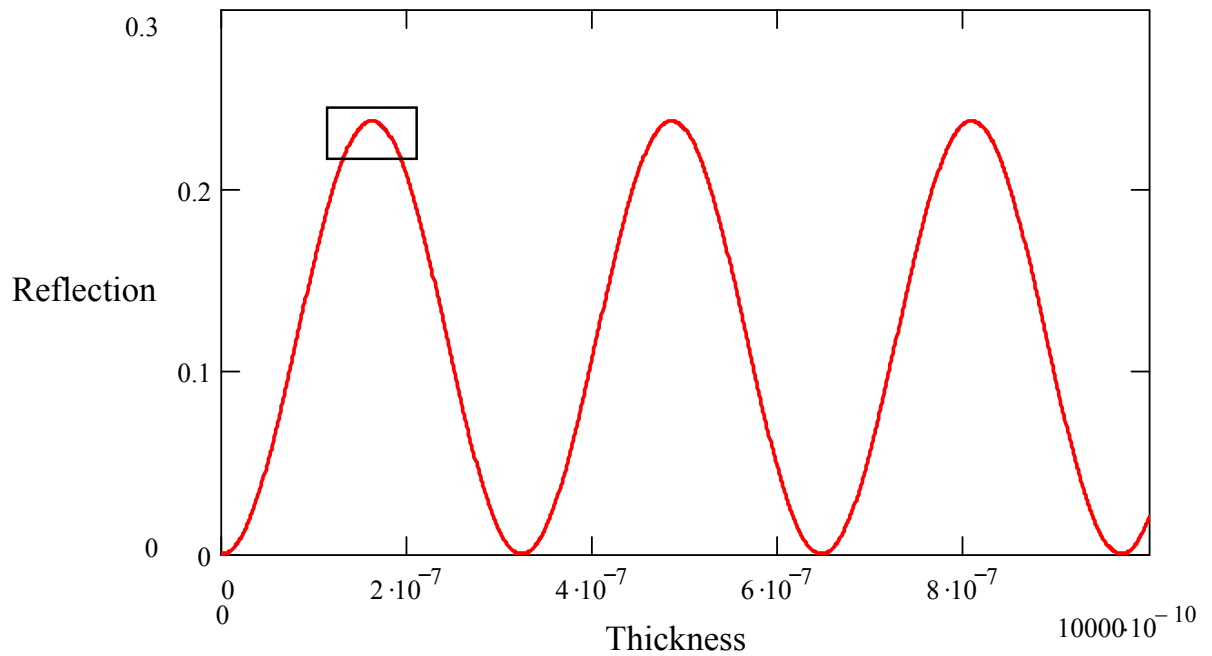

Fig. 7 Dependence of internal mirror reflectance on $\mathrm{TiO}_{2}$ film thickness at a wavelength of $1550 \mathrm{~nm}$. 


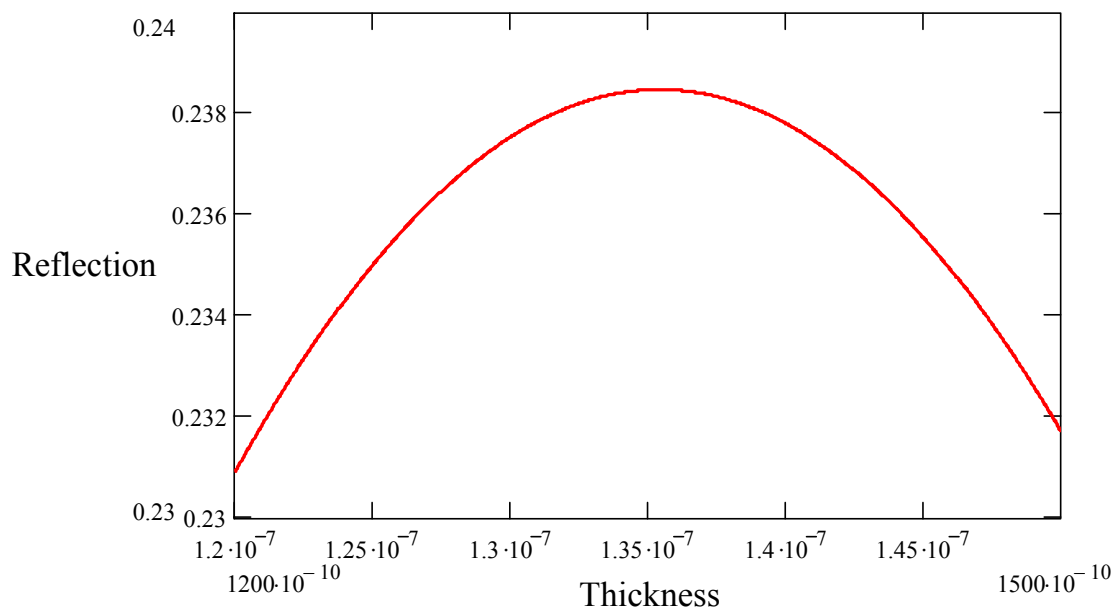

Fig. 8 First maximum in reflectance as a function of $\mathrm{TiO}_{2}$ film thickness at a wavelength of $1300 \mathrm{~nm}$.

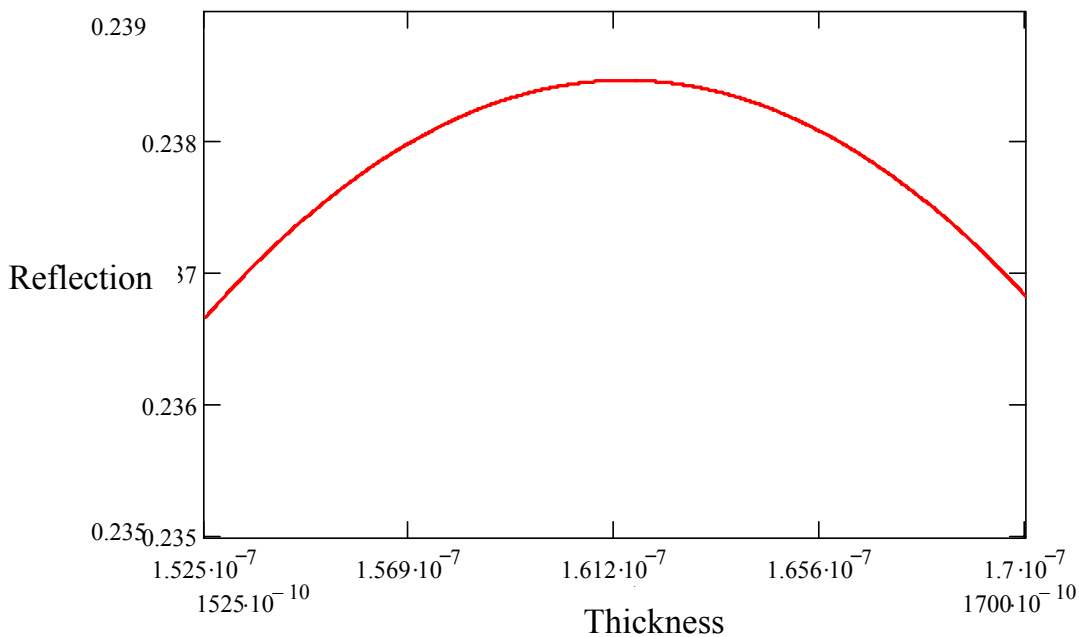

Fig. 9 First maximum in reflectance as a function of $\mathrm{TiO}_{2}$ film thickness at a wavelength of $1550 \mathrm{~nm}$. 


\section{Internal Mirror}

Electrical arc fusion-splicing technique for fabricating internal mirrors in continuous length of an optical fiber was introduced over a decade ago [13]. The fusion splicing machine is designed for connecting two fibers together with an electric arc. The basic configuration of the arc fusion splicing is shown in Fig 10. At first, two sorts of fibers $\left(\mathrm{TiO}_{2}\right.$ coated fiber and a normal fiber) are placed into the $\mathrm{V}$-grooves of the splicer. The distance between the two V-grooves holding the fibers is precisely controlled by a micro-positioner. An electric arc is initiated between the electrodes and the arc current is controlled to adjust the temperature at the splicing region to a proper level for melting the fiber ends.

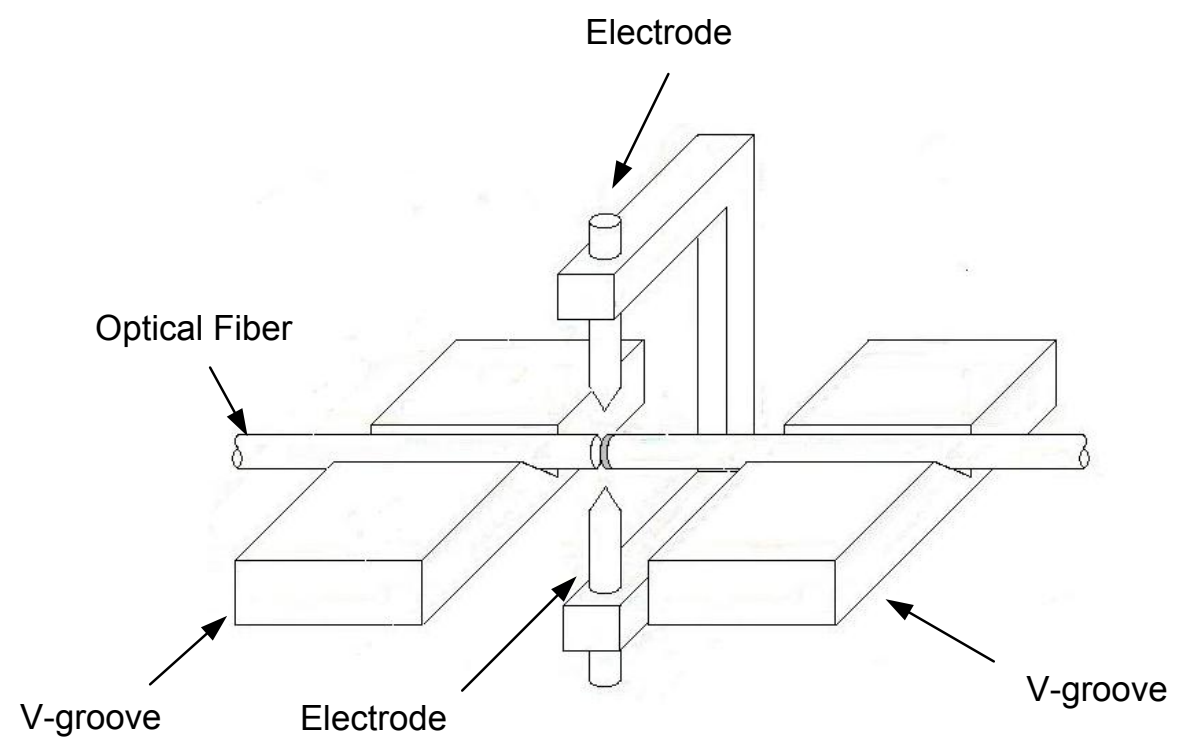

Fig. 10 Basic configuration of electric arc fusion splice. 
The FFPI sensor fabrication procedure [Fig. 11] and [Fig. 12] is as follows:

(1) Cleave one end of the 3-dB fiber coupler and terminate the other end of the fiber coupler in index matching gel for no reflection.

(2) Measure the Fresnel reflectance $\left(V_{\text {Fresnel }}\right)$ and splice to the cleaved end of fiber coupler a $\mathrm{TiO}_{2}$ coated fiber as an in-line fiber. Then monitor the reflectance from the first mirror [Fig.12] while applying an electric arc until a desired reflectance (about 5\%) is achieved.

Normal fiber

(a)

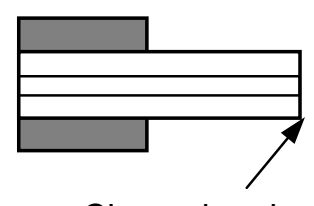

Cleaved end
$\mathrm{TiO}_{2}$ coated fiber

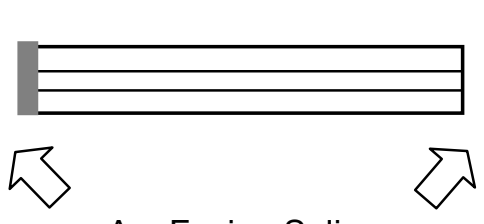

Arc Fusion Splice

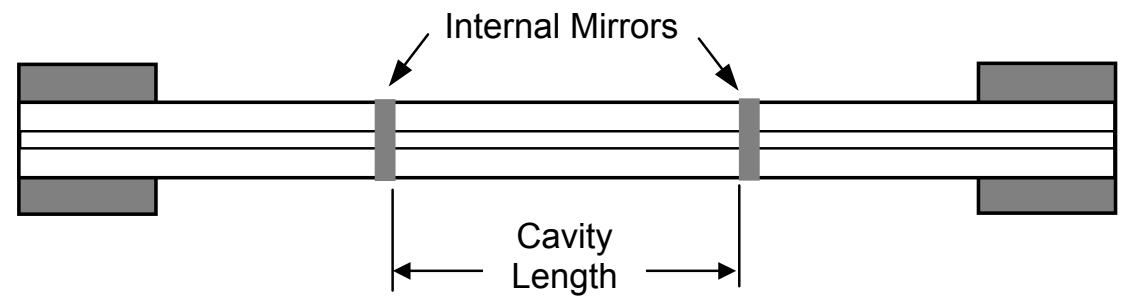

Fig. 11 FFPI sensor fabrication.

(a) Form the interferometer by arc fusion-splicing.

(b) Completed FFPI sensor with internal two mirrors. 
The reflectance can then be calculated using the relation given below, where $3.5 \%$ is the ideal reflectance value for the cleaved end fiber.

$$
R=3.5 \% \times \frac{V_{\text {Mirror }}}{V_{\text {Fresnel }}}
$$

where $R$ is the reflectance of the first mirror and $V_{\text {Mirror }}$ is the voltage observed on the oscilloscope.

The applied fusion parameters (arc current and duration time) are generally lower than those of a normal splice, and depend on the desired reflectance [14].

(3) After making one mirror, cleave to adjust the cavity length (about $12 \mathrm{~mm}$ ) from the first mirror, and then splice another coated fiber [Fig. 11] for a second mirror by the same method as the first splice.

The experimental setup shown in Fig. 12 is used for monitoring and fabricating the FFPI sensing element. The $1.3 \mu \mathrm{m}$ laser is modulated by the function generator and driven by the LD driver (Appendix A). After the light from the semiconductor laser diode passes through the $3 \mathrm{~dB}$ coupler, a part of the signal is reflected from the sensor. After passing through the coupler again, the reflected optical signal is converted into an electrical signal by a photodetector. The interference fringe can be displayed on an oscilloscope in a reflection-versus-time plot, as illustrated in Fig. 13. 


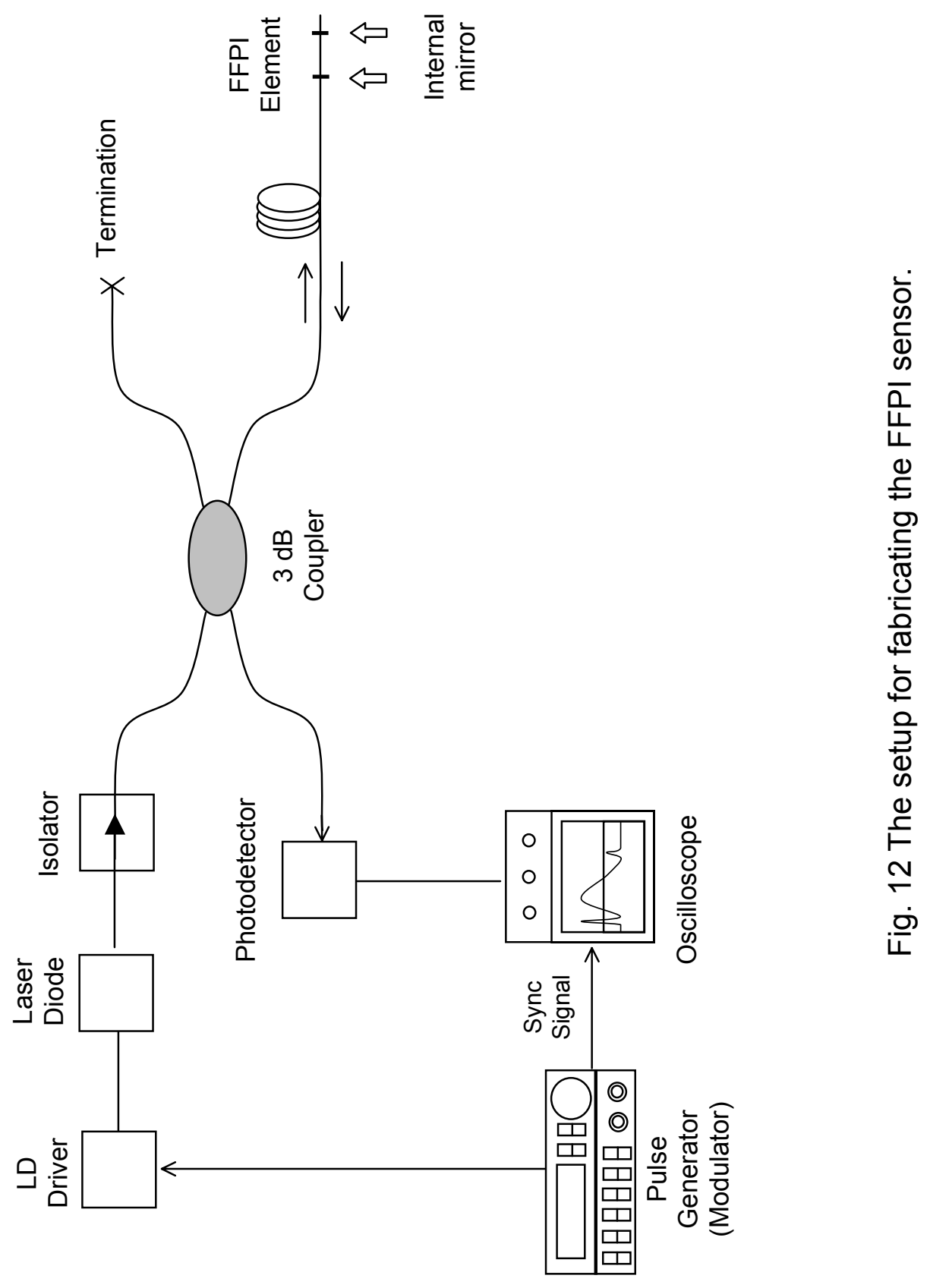




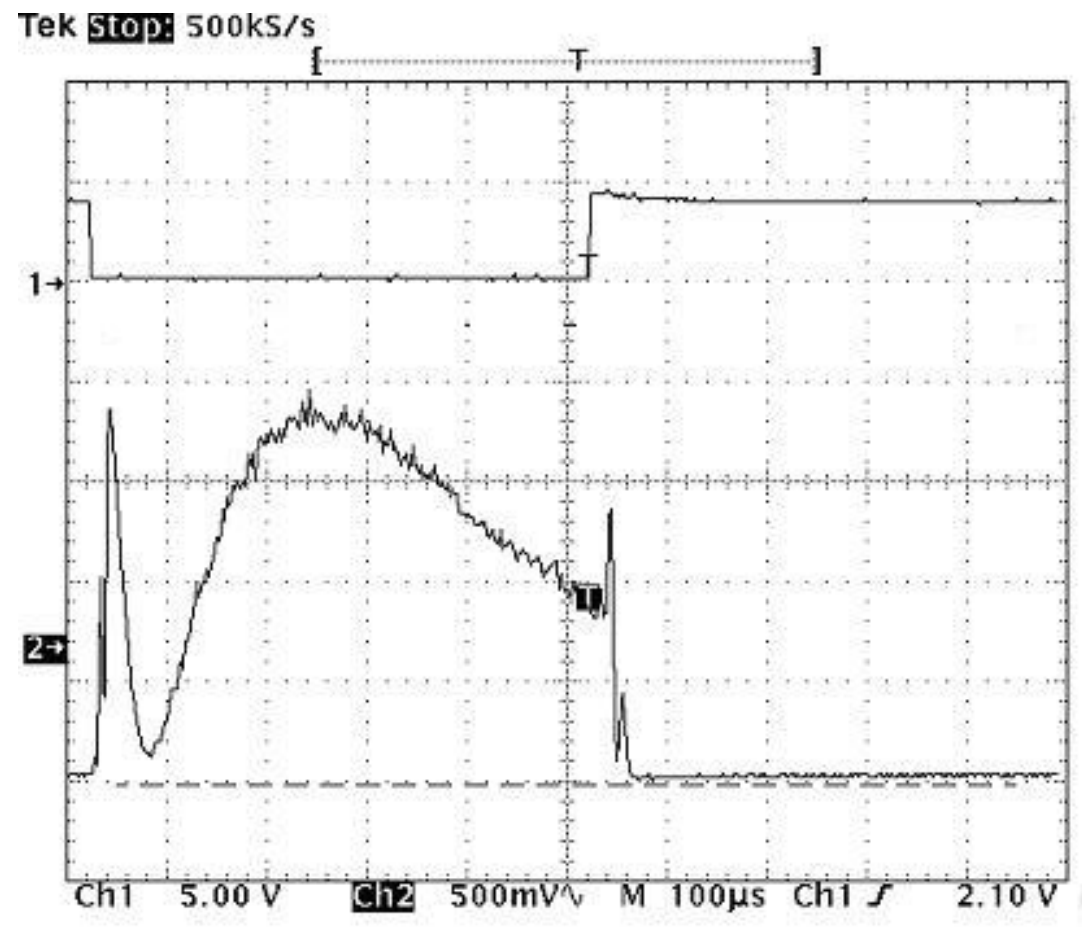

Fig. 13 Optical signal reflected from the sensor. 


\section{CHAPTER IV}

\section{EXPERIMENTAL PROCEDURE AND FIELD TEST RESULTS}

\section{A. Spark Plug Mounted Fiber Optic Pressure Sensor Fabrication}

Since the internal conditions inside the cylinder of an engine are sever, a special packaging technique for protecting the FFPI sensor element is needed. Gold coating and copper electroplating processes were employed for the high-pressure fiber sensor. The gold-coated and copper-electroplated fiber is embedded in a spark plug. To attach the fiber sensor in the spark plug, a narrow groove is cut in the metal body shell of the spark plug.

\section{The Gold Coating}

The FFPI elements are soaked in liquid gold and cured by firing in a furnace for several minutes, yielding a thin gold layer on the fiber surface [Fig. 14]. For good adhesion, this process (dipping \& curing) is repeated several times. Because of the difficulty of checking the gold coating status, the end reflectance of the gold-coated fiber was measured and a high reflectance value was considered as an indication for a good gold coating.

A gold-coated fiber not only protects the fiber sensing element, but also enables additional electroplating on top of it. Because of the high reflectance of gold, 
when the coating was performed on the FFPI sensor element, the end of the goldcoated fiber was broken to eliminate end reflections. Fig. 15 illustrates a gold-coated FFPI sensor.

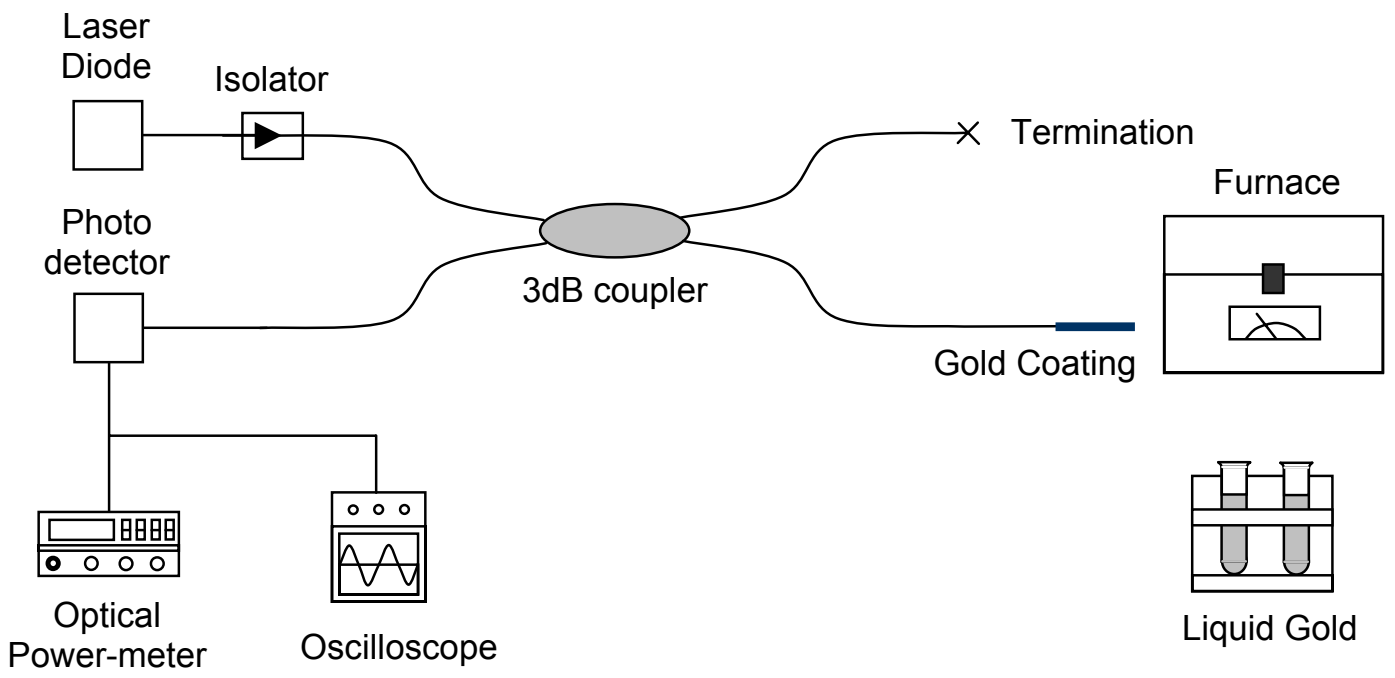

Fig. 14 The setup for monitoring the reflectance of the gold-coated fiber.

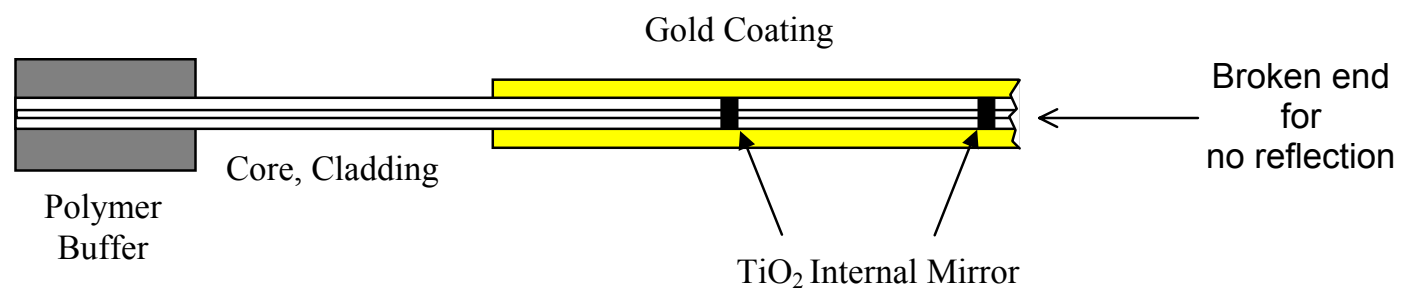

Fig. 15 Gold-coated FFPI sensor. 


\section{Copper Electroplating}

After the gold coating procedure, an electrolysis reaction is used to electroplate the gold-coated fiber with copper (melting temperature: $1083^{\circ} \mathrm{C}$ ) [15][16]. As shown in Fig. 16, the anode and cathode in the electroplating solution are connected to an external power supply. The gold-coated fiber sensor (Cathode) is connected to the negative electrode and the copper plate (Anode) is connected to the positive electrode. The copper plate needs to be clean. The container is filled with Copper(II) Chloride Dihydrate $\left(\mathrm{CuCl}_{2} \bullet 2 \mathrm{H}_{2} \mathrm{O}\right)$ solution enough to immerse the gold-coated fiber and the copper plate.

The electroplating process is as follows: When the external power supply is turned on, the copper plate is oxidized to $\mathrm{Cu}^{2+}$ by losing two electrons at the anode,

$$
\mathrm{Cu} \rightarrow \mathrm{Cu}^{2+}+2 e^{-}
$$

The solution $\mathrm{CuCl}_{2}$ ionizes in water into $\mathrm{Cu}^{2+}$ and two parts of $\mathrm{Cl}^{-}$,

$$
\mathrm{CuCl}_{2} \rightarrow \mathrm{Cu}^{2+}+2 \mathrm{Cl}^{-}
$$

and, $\mathrm{Cu}^{2+}$ ions are reduced to metallic $\mathrm{Cu}$ at the negatively charged cathode

$$
\mathrm{Cu}^{2+}+2 e^{-} \rightarrow \mathrm{Cu}
$$

Meanwhile, the copper ions in the solution are replaced by oxidation of copper from the copper plate anode and the chloride ions are oxidized. 
The polishing process is prerequisite to obtain an evenly-coated surface. The thickness of the electroplated copper is about 0.005 inches. The metal-coated FFPI sensing element is illustrated in Fig 17.

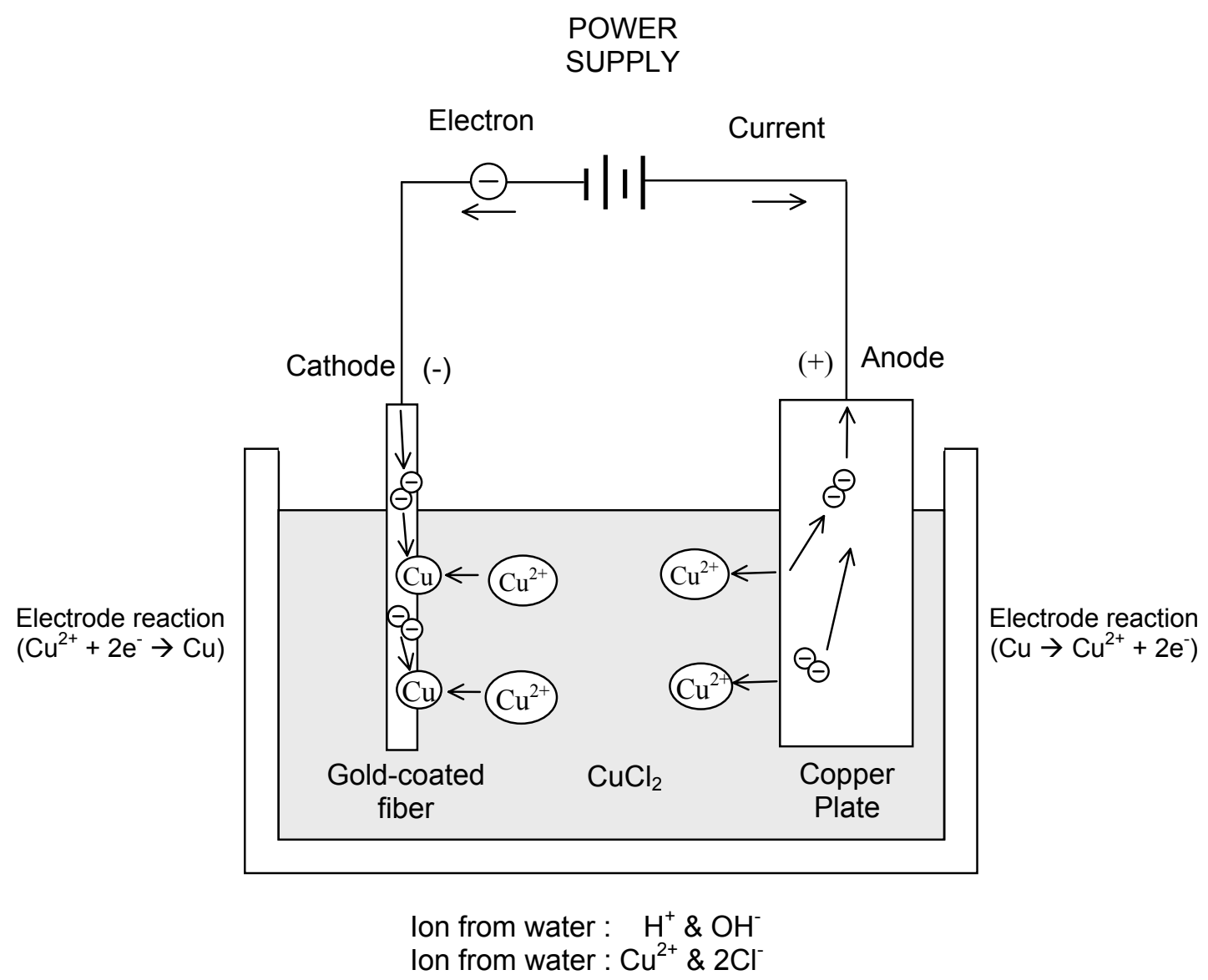

Fig. 16 The setup for copper electroplating of a gold-coated fiber. 


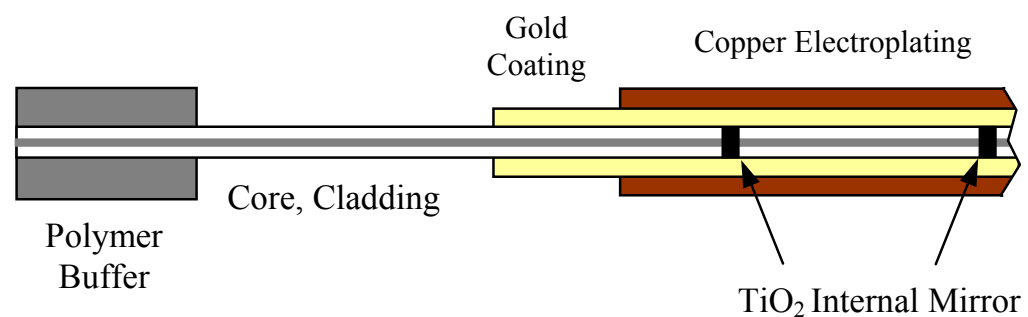

Fig. 17 The gold-coated and copper electroplated FFPI sensor.

\section{Spark Plug}

For this research, commercially available standard automotive spark plugs were used. The spark plug, which enables the engine to generate power by ignition of air-fuel mixture in the cylinder, contained the FFPI sensor.

The Fig. 18 shows the configuration of the spark plug mounted fiber optic sensor. As shown, the FFPI sensor is directly attached to the side of the spark plug. The metallic body shell of the spark plug was cut by a very thin saw blade about 0.005 inches in width. Depth of the sawn groove is about $0.007-0.008$ inches. The width and depth of the groove provide a cavity slightly larger than those of the gold-coated and the copper-electroplated fiber. An end mill 0.03 inches in diameter is also used to cut a larger groove for a stainless steel tube which provides protection for the fiber where it enters the spark plug. Silver-soldering was used to solder the stainless steel 
tube at the top of the metal casing. A high-temperature epoxy was used for bonding the fiber interferometer inside the groove of the casing.

After the FFPI sensor was embedded into the groove of the body shell through the stainless steel tube, a braided stainless steel jacket was applied to protect the rest of the fiber sensor. Finally the input side of the fiber sensor was spliced to a patch cord that was terminated with an optical connector (3M type SC single mode APC connector) to enable connection to the SCU. The spark plug attached fiber sensor assembly for use in an automotive engine is illustrated in Fig. 19.

When the spark plug-embedded fiber sensor is mounted in a port in the cylinder head, the ceramic insulator inside the metal shell is directly exposed to the incylinder pressure. When the engine fires and the pressure increase, the ceramic insulator is forced upward, against the upper lip of the metal casing. This causes the longitudinal strain in the metal casing to increase, and this strain is also experienced by the embedded FFPI sensing element. 


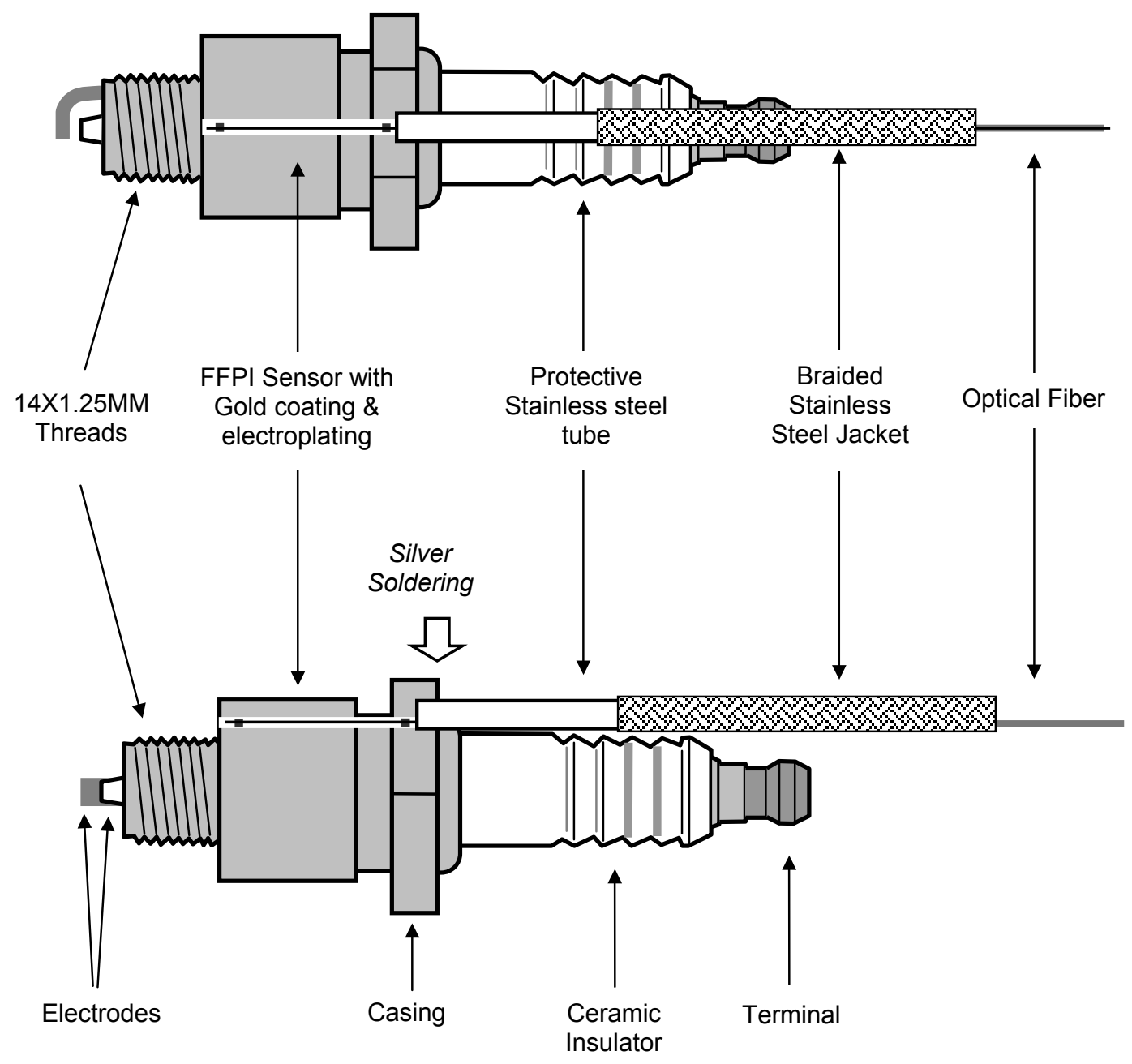

Fig. 18 Configuration for spark plug mounted fiber optic sensor. 


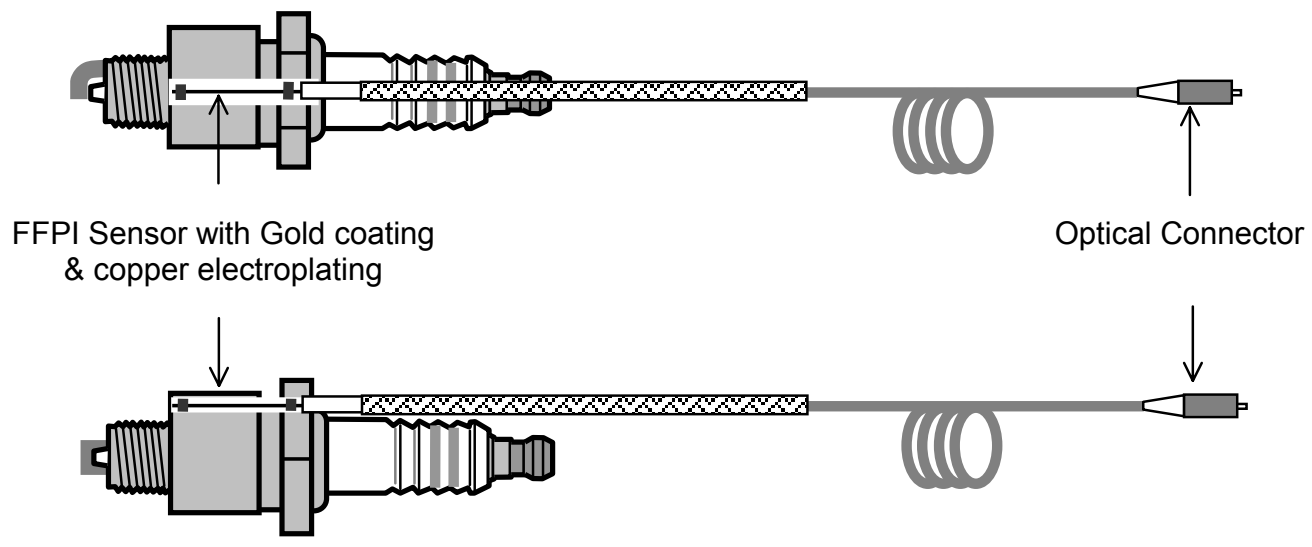

Fig. 19 Connectorized fiber sensor assembly for use in automotive engine.

\section{B. Field Test and Results}

Field tests to evaluate the performance of the fiber sensor in an automotive engine were carried out at Texas A\&M Riverside Campus test site in Brazos County, TX.

\section{Deadweight Calibration}

Before carrying out filed tests, deadweight calibration was performed to calibrate the pressure response of the fiber optic sensor. At first, the spark-plugmounted fiber sensor was installed in the test port of the setup [Fig. 20]. The pressure 
release valve was closed, the deadweight pressure unit was pressurized until a desired pressure (1000 - 3500psi) is obtained. Then, the pressure release valve was quickly released and the voltage signal from the sensor was monitored on an oscilloscope.

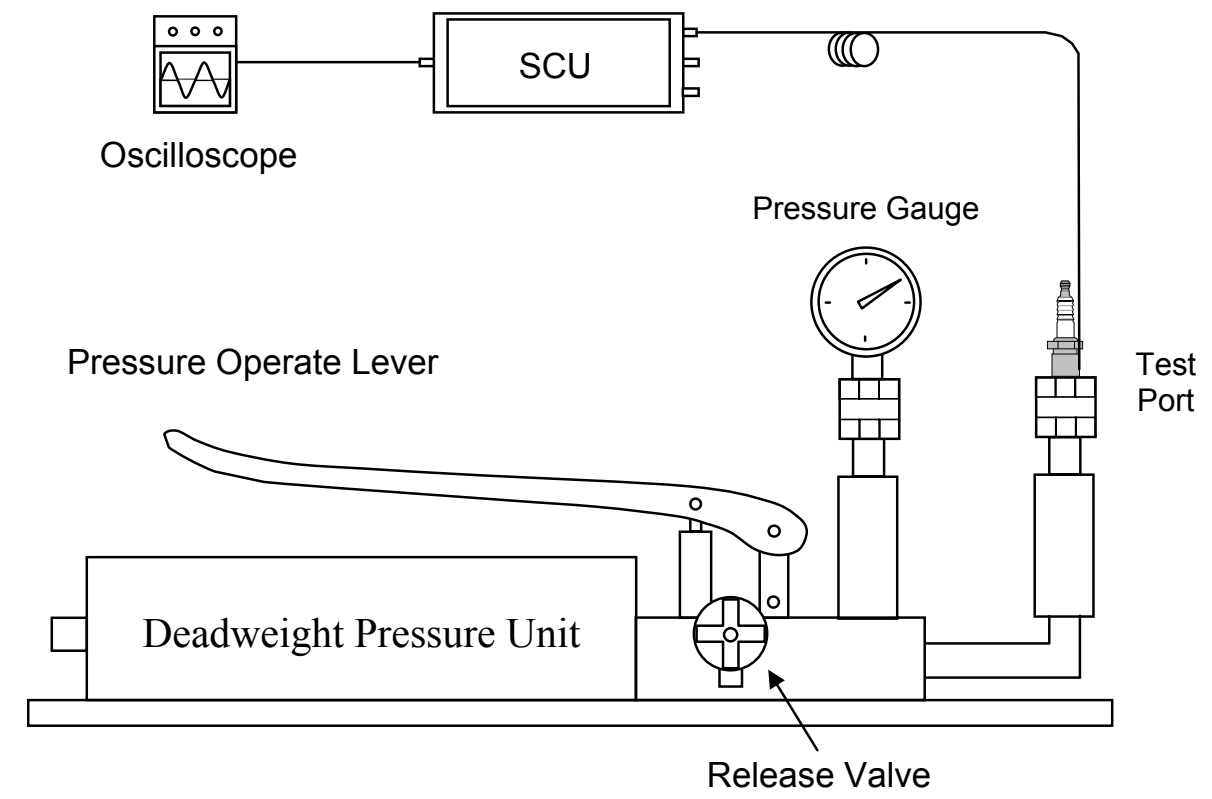

Fig. 20 Deadweight test setup for calibration.

Table I shows the calibration constants and sensitivity of the sensor sample. The sensitivity is given in psi per $\pi$ radian optical phase shift produced by the pressure in the FFPI sensor. 
TABLE I

The calibration constant and sensitivity.

\begin{tabular}{|c|c|c|c|c|c|c|c|}
\hline Sample & $\begin{array}{l}\text { Desired } \\
\text { Pressure }\end{array}$ & 1000 psi & 1500 psi & 2000 psi & 2500 psi & 3000 psi & 3500 psi \\
\hline \multirow[t]{2}{*}{1} & $\begin{array}{c}\text { Calibration } \\
\text { constant }\end{array}$ & 2650 & 1850 & 1320 & 1072 & 828 & 750 \\
\hline & Sensitivity & $1325 \mathrm{psi} / \pi$ & $925 \mathrm{psi} / \pi$ & $660 \mathrm{psi} / \pi$ & $536 \mathrm{psi} / \pi$ & $414 \mathrm{psi} / \pi$ & $375 \mathrm{psi} / \pi$ \\
\hline \multirow[t]{2}{*}{2} & $\begin{array}{c}\text { Calibration } \\
\text { constant }\end{array}$ & 2500 & 1750 & 1210 & 828 & 760 & 550 \\
\hline & Sensitivity & $1250 \mathrm{psi} / \pi$ & $875 \mathrm{psi} / \pi$ & $605 \mathrm{psi} / \pi$ & $414 \mathrm{psi} / \pi$ & $380 \mathrm{psi} / \pi$ & $275 \mathrm{psi} / \pi$ \\
\hline \multirow[t]{2}{*}{3} & $\begin{array}{c}\text { Calibration } \\
\text { constant }\end{array}$ & 1450 & 627 & 405 & 260 & 223 & 142 \\
\hline & Sensitivity & $725 \mathrm{psi} / \pi$ & $313 \mathrm{psi} / \pi$ & $202 \mathrm{psi} / \pi$ & $130 \mathrm{psi} / \pi$ & $111 \mathrm{psi} / \pi$ & $71 \mathrm{psi} / \pi$ \\
\hline \multirow[t]{2}{*}{4} & $\begin{array}{c}\text { Calibration } \\
\text { constant }\end{array}$ & 2610 & 1750 & 1190 & 920 & 725 & 675 \\
\hline & Sensitivity & $1305 \mathrm{psi} / \pi$ & $875 \mathrm{psi} / \pi$ & $595 \mathrm{psi} / \pi$ & $460 \mathrm{psi} / \pi$ & $362 \mathrm{psi} / \pi$ & $337 \mathrm{psi} / \pi$ \\
\hline \multirow[t]{2}{*}{5} & $\begin{array}{c}\text { Calibration } \\
\text { constant }\end{array}$ & 1250 & 945 & 715 & 550 & 450 & 385 \\
\hline & Sensitivity & $625 \mathrm{psi} / \pi$ & $472 \mathrm{psi} / \pi$ & $357 \mathrm{psi} / \pi$ & $275 \mathrm{psi} / \pi$ & $225 \mathrm{psi} / \pi$ & $192 \mathrm{psi} / \pi$ \\
\hline \multirow[t]{2}{*}{6} & $\begin{array}{c}\text { Calibration } \\
\text { constant }\end{array}$ & 5500 & 4650 & 3560 & 2490 & 2100 & 1700 \\
\hline & Sensitivity & $2759 \mathrm{psi} / \pi$ & $2325 \mathrm{psi} / \pi$ & $1780 \mathrm{psi} / \pi$ & $1245 \mathrm{psi} / \pi$ & $1050 \mathrm{psi} / \pi$ & $850 \mathrm{psi} / \pi$ \\
\hline
\end{tabular}




\section{Test Configuration}

Figure 21 shows the experimental setup for gasoline powered automotive engine in Geo Metro. The Geo Metro has three cylinders and one of them was installed by a spark plug containing the FFPI element, which is used for the ignition of the engine. The reference transducer, a piezoelectric sensor, was also mounted in the same cylinder of the engine and was used as a reference sensor for comparison with the performance of the spark-plug-embedded FFPI sensor. The FFPI element had $12 \mathrm{~mm}$ cavity length and about $5 \%$ reflectance. The engine was operated up to around 3500 revolutions per minute (RPM).

A commercial Signal Conditioning Unit (SCU) computes and displays the pressure as a function of time from a reflected optical signal. The SCU contains a 1300nm Distributed Feedback (DFB) laser diode, a photodetector, a coupler, a LD driver and a micro controller for processing the optical signal. The laser diode in the SCU is driven by saw-tooth pulse modulation and the modulated optical power signal was directed to the FFPI sensing element through a coupler within the SCU unit. The SCU monitors the reflected optical signal from the FFPI element and uses this information to determine the strain in the SCU.

As in-cylinder pressure changes, the strain caused by the pressure in the spark plug casing also changes. 


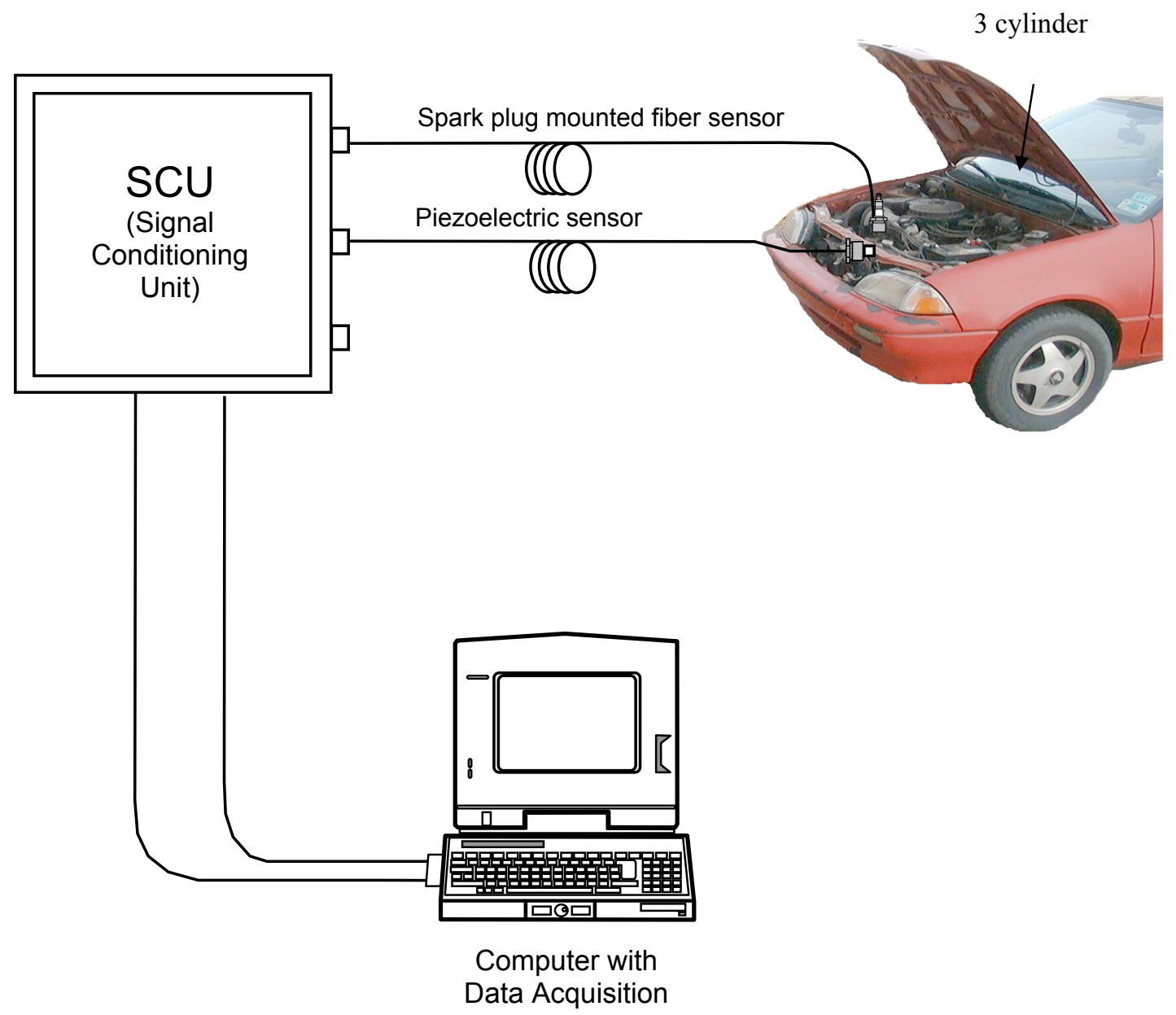

Fig. 21 Setup for measure in-cylinder pressure of a 3-cylinder automotive engine. 


\section{Test Result}

These results show the ability of the FFPI sensor to respond to in-cylinder pressure changes during normal operation of the spark plug. The pressure data from the spark-plug-mounted fiber optic sensors and a commercial piezoelectric sensor mounted in the same cylinder of the engine are shown in Figure 22 - Figure 28. The comparison traces are generally matched except for a reset area in the spark-plugmounted sensors in each cycle. During the test, the engine sensor was evaluated up to around 3500 revolutions per minute (RPM). Fig. 28 compares pressure data from the spark-plug-mounted fiber optic sensors to data obtained with a commercial piezoelectric sensor mounted in the same cylinder of the engine, and those of another spark-plug-mounted fiber sensor installed in an adjacent cylinder.

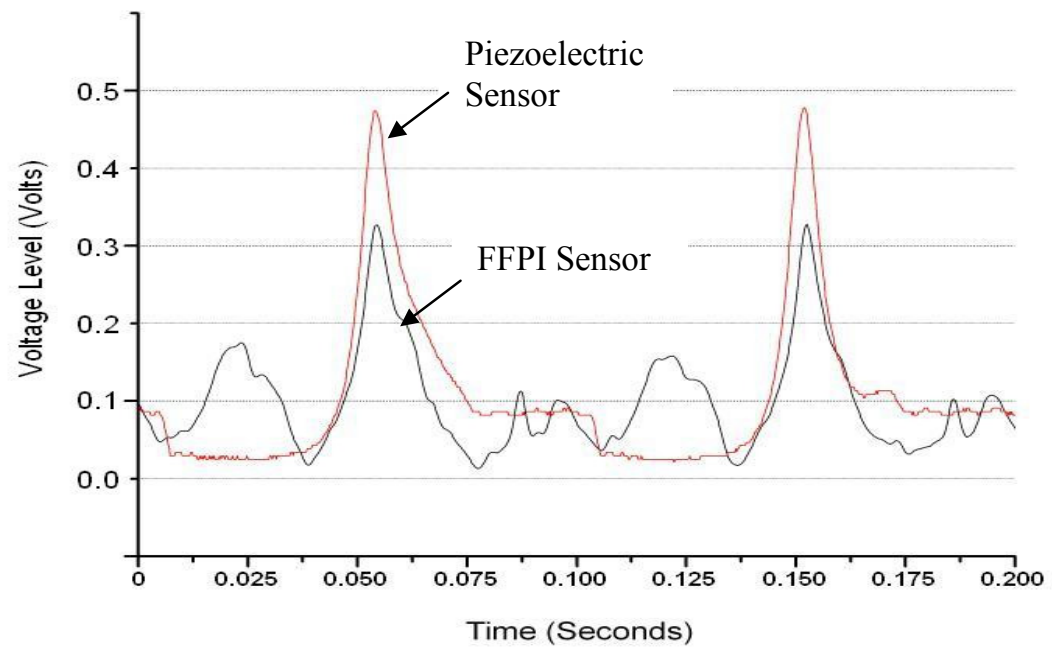

Fig. 22 In-cylinder pressure comparison between a spark-plug-mounted optic sensor and a piezoelectric sensor in around 1200rpm. 


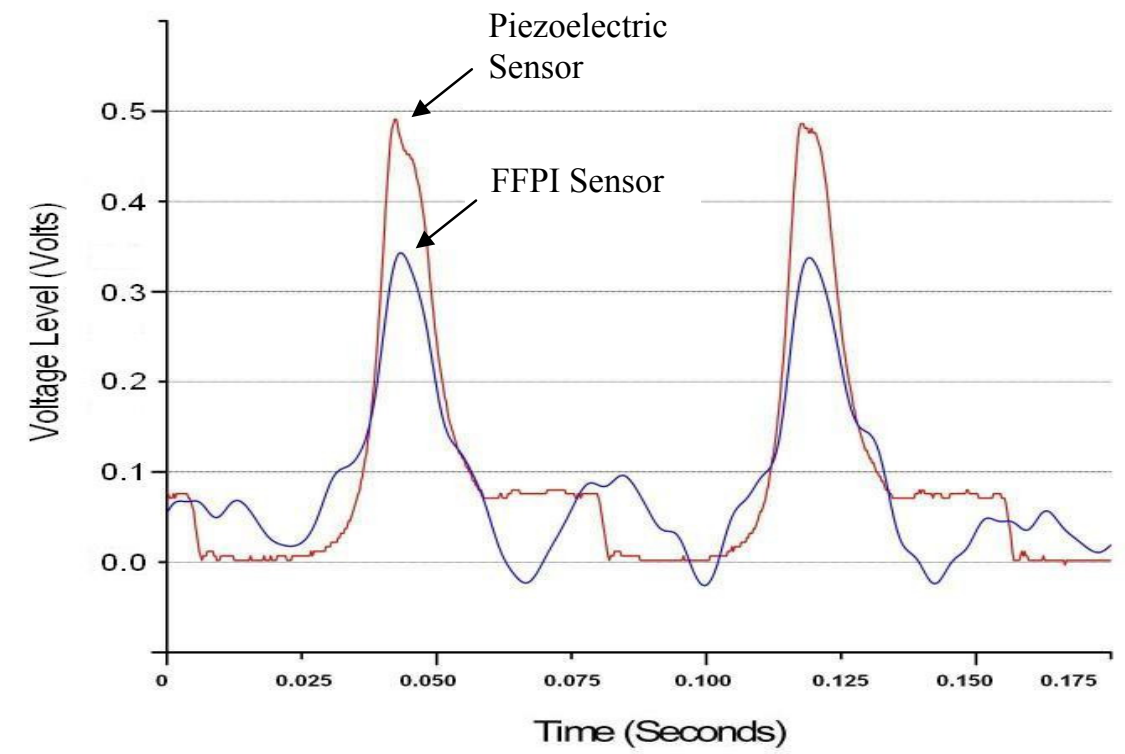

Fig. 23 In-cylinder pressure comparison between a spark-plug-mounted optic sensor and a piezoelectric sensor in around 1500rpm.

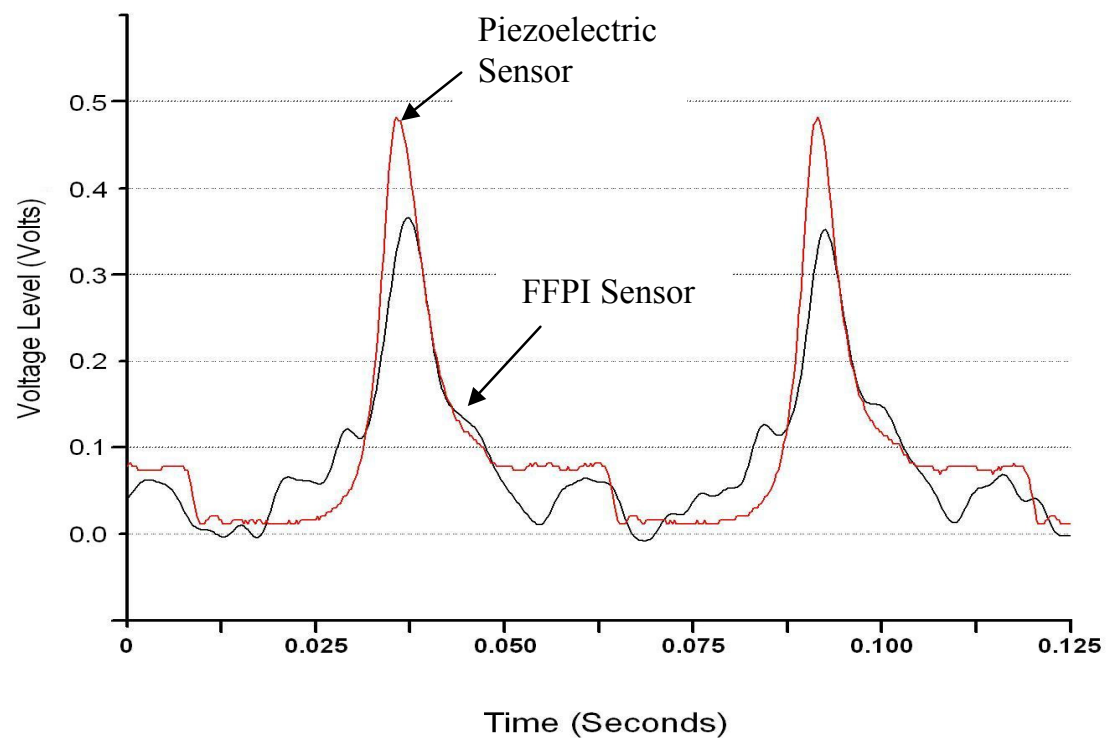

Fig. 24 In-cylinder pressure comparison between a spark-plug-mounted optic sensor and a piezoelectric sensor in around 2000rpm. 


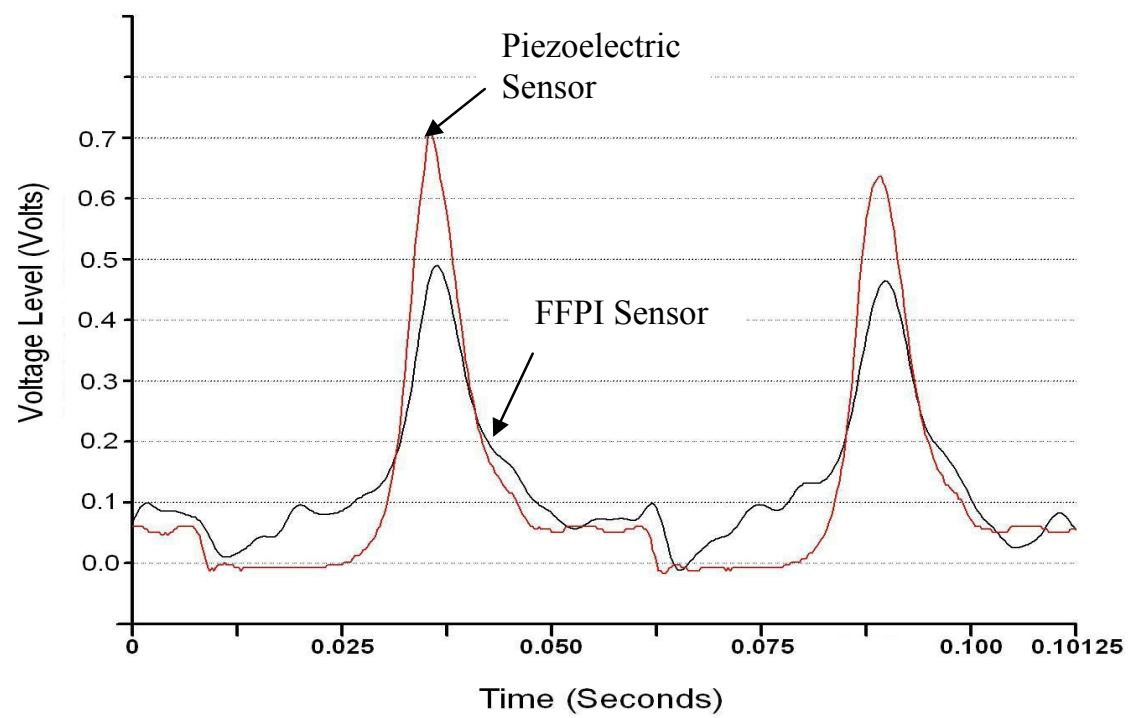

Fig. 25 In-cylinder pressure comparison between a spark-plug-mounted optic sensor and a piezoelectric sensor in around 2500rpm.

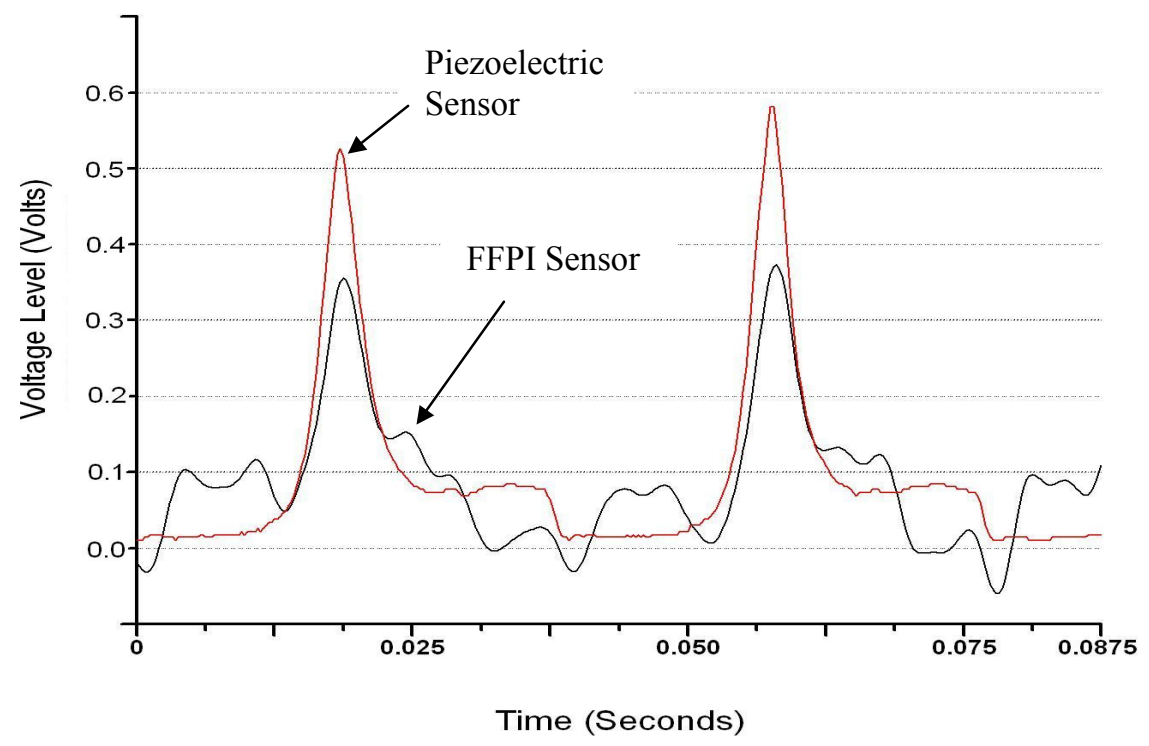

Fig. 26 In-cylinder pressure comparison between a spark-plug-mounted optic sensor and a piezoelectric sensor in around 3000rpm. 


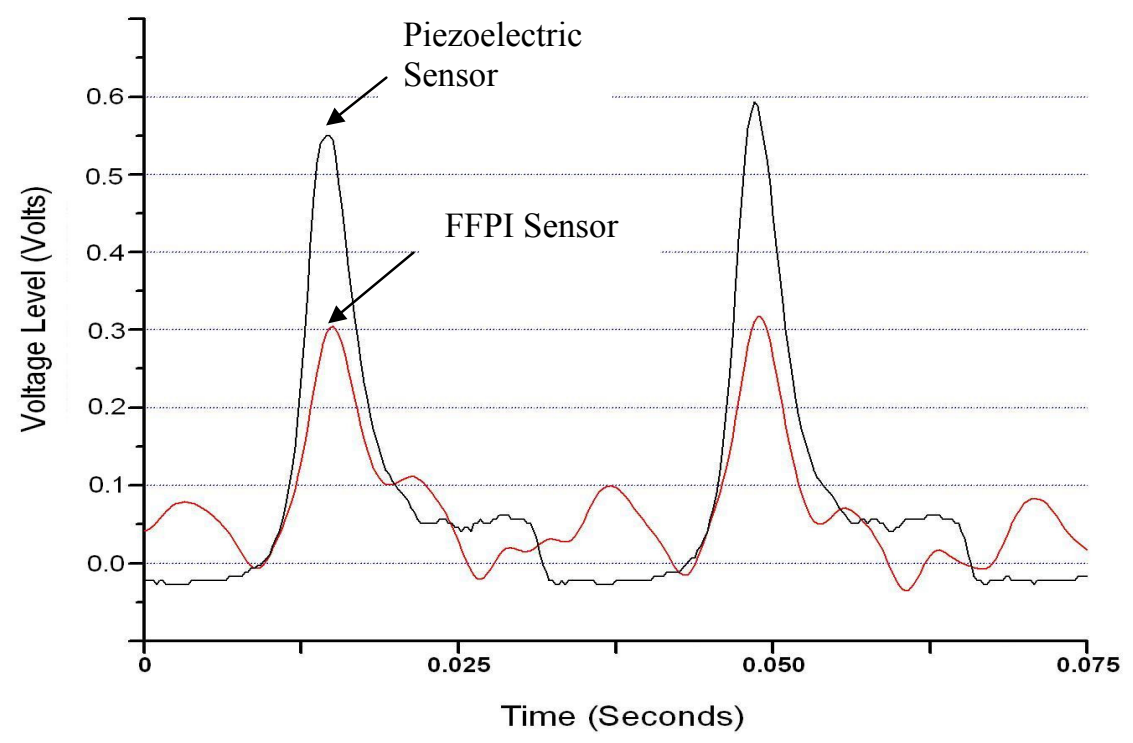

Fig. 27 In-cylinder pressure comparison between a spark-plug-mounted optic sensor and a piezoelectric sensor in around 3500rpm.

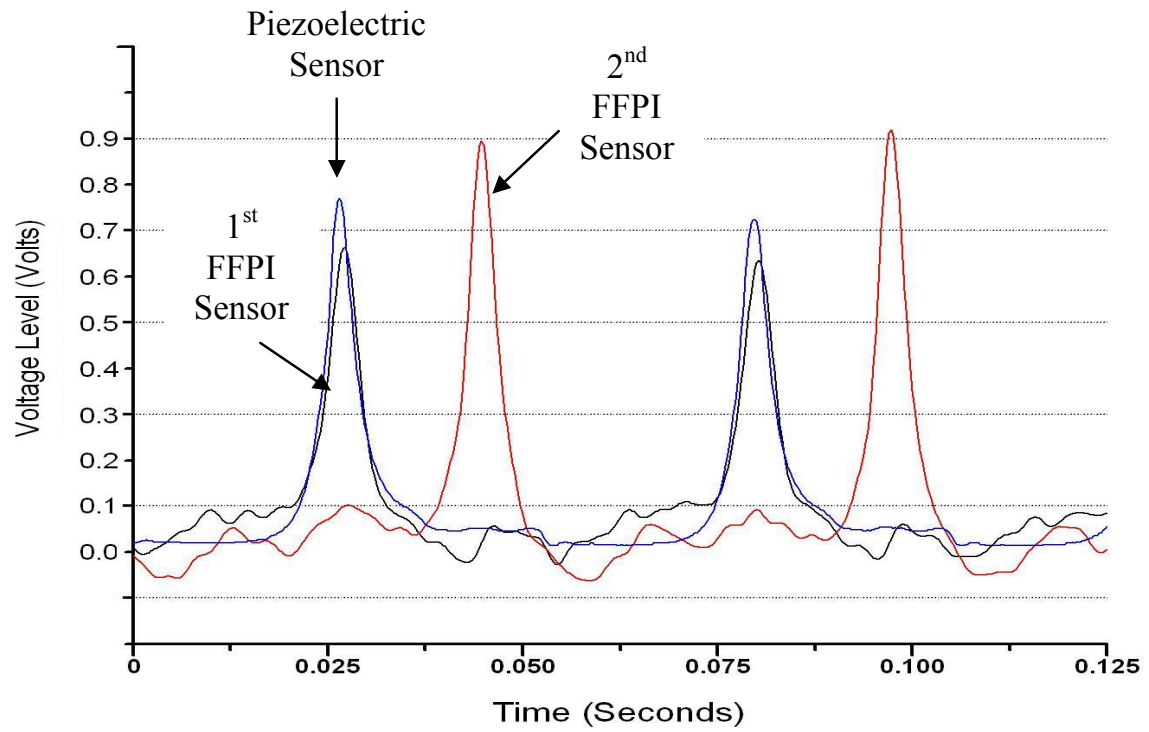

Fig. 28 In-cylinder pressure comparison between two spark-plug-mounted optic sensors and a piezoelectric sensor in around 2500rpm. 


\section{CHAPTER V}

\section{EXPERIMENTAL PROCEDURE AND TEST FOR VCSEL}

\section{A. Experimental Investigation of VCSEL}

The setup used for this investigation is shown in Fig 29. The 1.5 $\mu \mathrm{m}$ VCSEL diode is controlled and driven by the laser driving circuit (Appendix B) and modulated by a function generator.

Basically, this is the same setup as that used for the DFB laser, except that because there is no pigtailed $1.5 \mu \mathrm{m}$ single mode VCSEL diode available, the light from the VCSEL diode needs to be coupled into the fiber. To couple the light from the VCSEL diode into the fiber, an anti-reflection coated lens for the spectral regime is used. After coupling into the fiber, the light passes through a $3 \mathrm{~dB}$ coupler, and a part of it is reflected from the sensor. The reflected optical signal is converted into an electrical signal by the photodetector. After passing through the coupler again, the interference fringes are displayed on an oscilloscope.

Because the VCSEL has a very low threshold current of about $1.09 \mathrm{~mA}$ $1.15 \mathrm{~mA}$ and a maximum current of only around $12.5 \mathrm{~mA}$, the biasing and modulation should be very carefully controlled. To avoid damage of the laser diode and properly control the current, a simple VCSEL driving circuit with dc battery is used. The voltage-spike is not allowed to exceed the maximum current of the VCSEL with this driving circuit. 


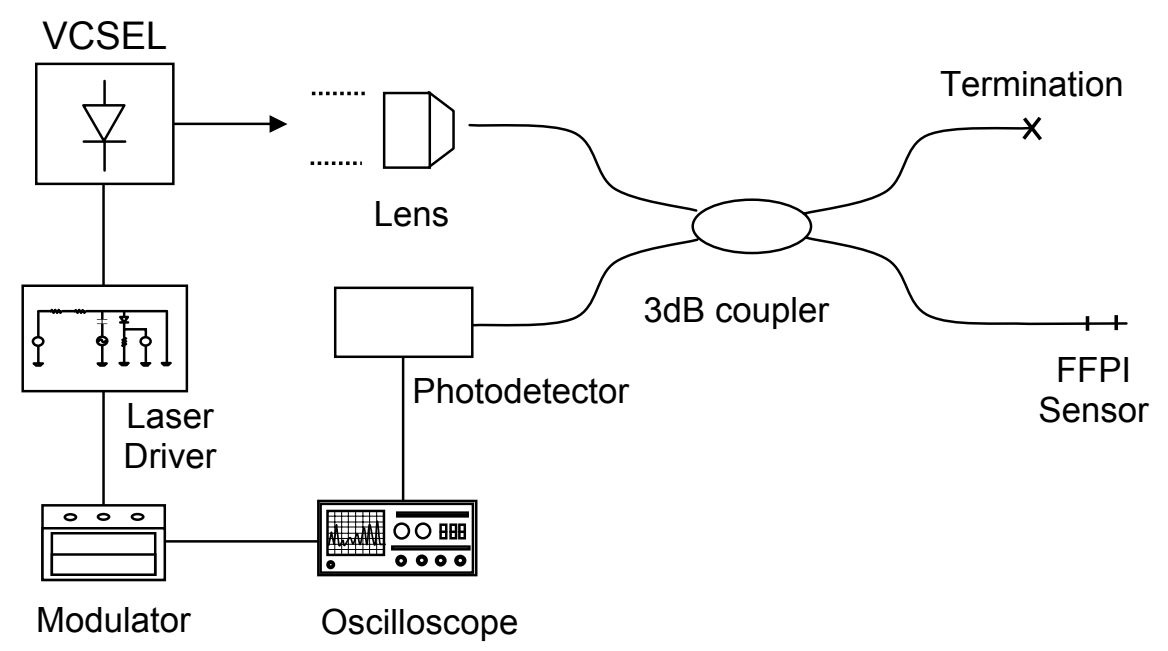

Fig. 29 Experimental setup for VCSEL.

To monitor the FFPI sensor the VCSEL diode is modulated with a timevarying drive current. The reflected light from the FFPI sensor varies with time and produces a fringe pattern in response to the modulation of the laser.

The effect of increasing the bias current of the VCSEL diode on the FFPI sensor response is shown in Fig 30. A saw-tooth waveform is applied with a fixed modulation current of $0.6 \mathrm{~mA}$ at a frequency of $1 \mathrm{kHz}$. As the bias current increases, the starting point of the fringes changes and the number of fringes also increases.

The response of the FFPI sensor to various modulation current amplitudes of the VCSEL diode at a fixed frequency of $1 \mathrm{kHz}$, is shown in Fig. 31 . Like the effect of the dc bias current increase, the number of visible fringes, also increase in this case as the modulation current amplitude is increased. 
Fig 32 shows the effect of modulation frequency on the observed sensor response. With a fixed bias current of $2.4 \mathrm{~mA}$ and a modulation current amplitude of $0.8 \mathrm{~mA}$, the increase of modulation frequency does not affect the fringe pattern and the number of fringes.
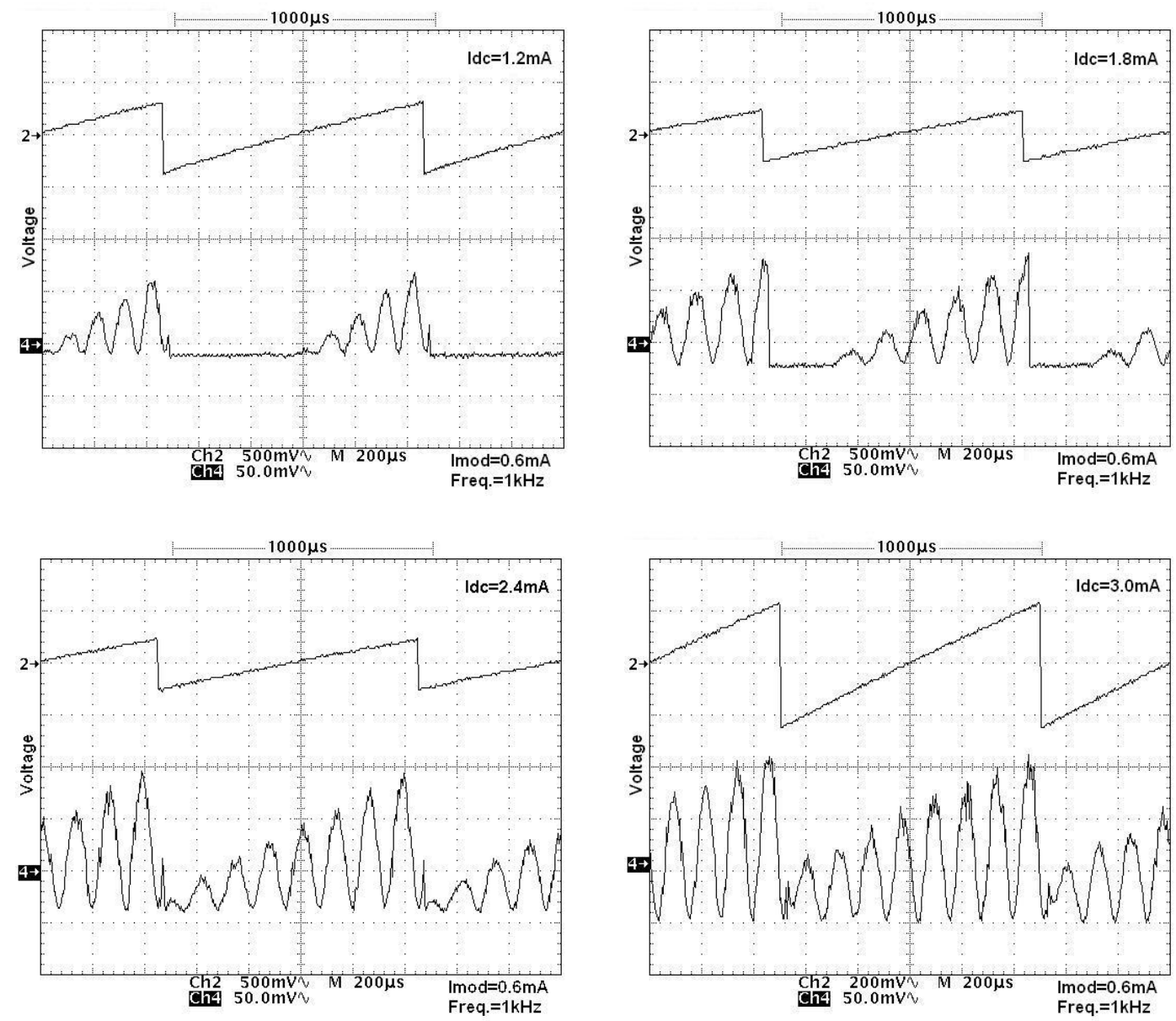

Fig. 30 Temporal dependence of sensor output power using VCL1550 VCSEL light source for saw-tooth modulating waveforms at different bias current levels. In each case the modulation peak to peak amplitude is $0.6 \mathrm{~mA}$, the horizontal scale is $200 \mu \mathrm{s} / \mathrm{div}$, and modulation frequency is $1 \mathrm{kHz}$. In each frame the upper trace is the modulation current and the lower trace is the sensor response. 

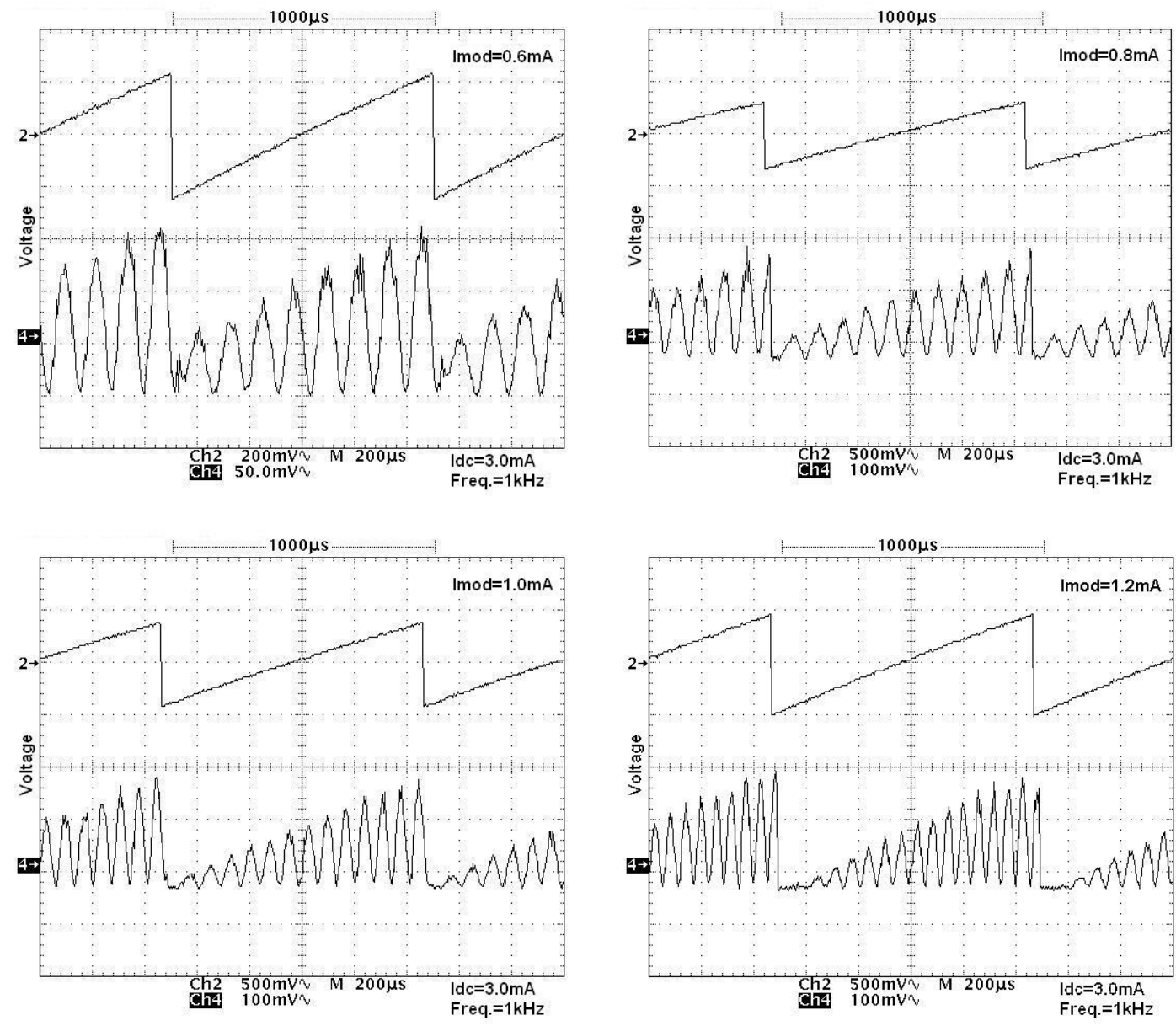

Fig. 31 Temporal dependence of sensor output power using VCL1550 VCSEL light source for saw-tooth modulating waveforms at different modulation current levels. In each case the dc bias current is $3.0 \mathrm{~mA}$, the horizontal scale is $200 \mu \mathrm{s} /$ div, and modulation frequency is $1 \mathrm{kHz}$. In each frame the upper trace is the modulation current and the lower trace is the sensor response. 

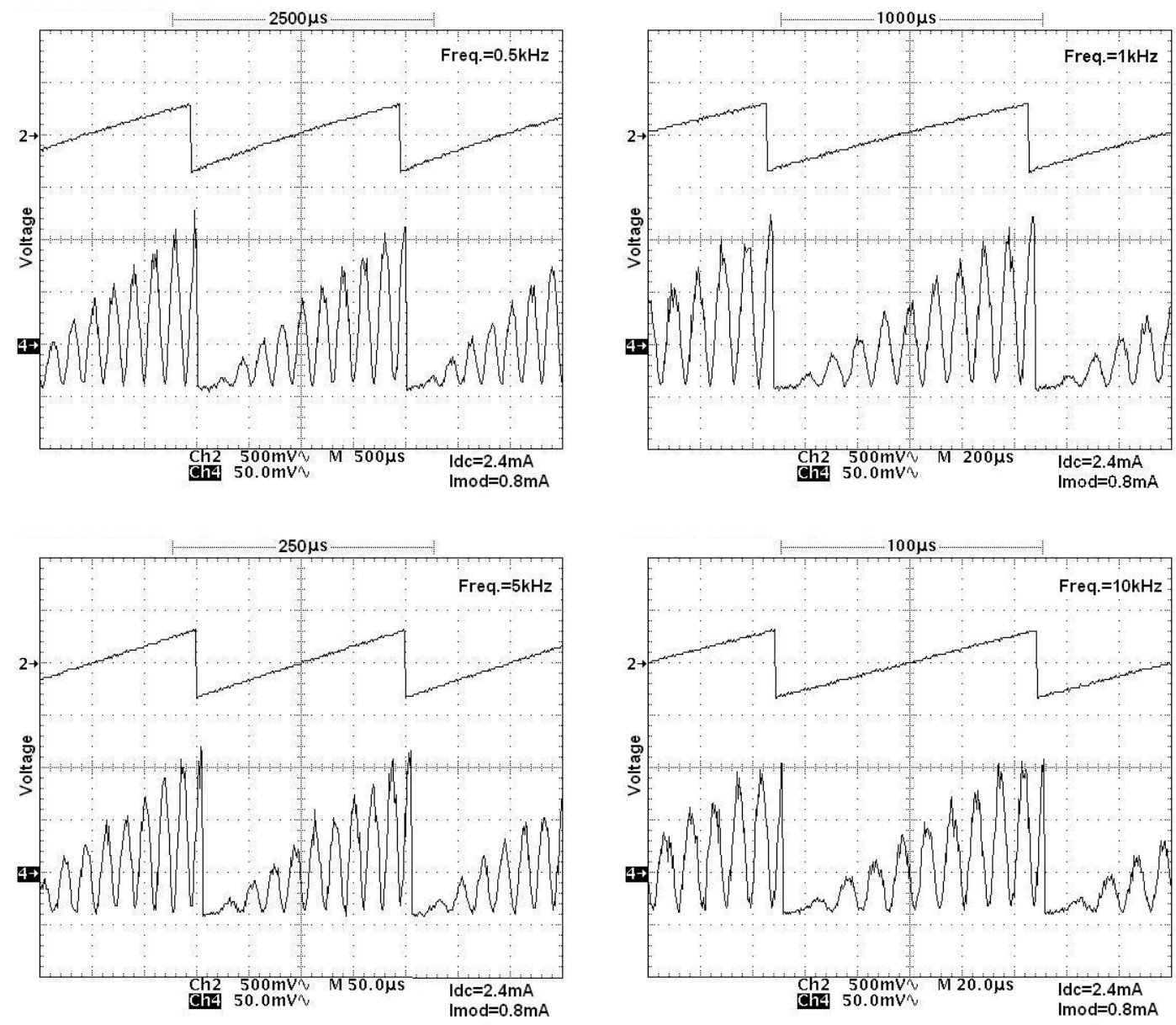

Fig. 32 Temporal dependence of sensor output power using VCL1550 VCSEL light source for saw-tooth modulating waveforms at different modulation frequency. In each case the dc bias current is $2.4 \mathrm{~mA}$ and the modulation peak to peak amplitude is $0.8 \mathrm{~mA}$. In each frame the upper trace is the modulation current and the lower trace is the sensor response. 


\section{B. Dependence of Fringe Patterns on VCSEL Spectral Characteristics}

To have a good fringe pattern, an FFPI sensor using VCSEL diode as light source should be operated with certain combination of bias current, modulation current and modulation frequency. Fig. 33 Shows the proper operating region for FFPI sensor with a VCSEL with saw-tooth wave modulation at $1 \mathrm{kHz}$ modulation frequency.

The black squares region represents improper operating regions. The circles represent proper operating regions. Fig. 34 shows the fringe pattern for the VCSEL diode bias and modulation currents at the (1)(2)(3)(4)(5) and (6), marked points in Fig. 33.

The fringe patterns at regions (1),(2) and (5), do not cover the full modulation cycle. The fringe patterns at point (3) is limited to few fringes. The fringe patterns for point (6) does not follow the modulation current function shape. The best operating combination of the bias and modulation current is designated at (4) in Fig. 34. 


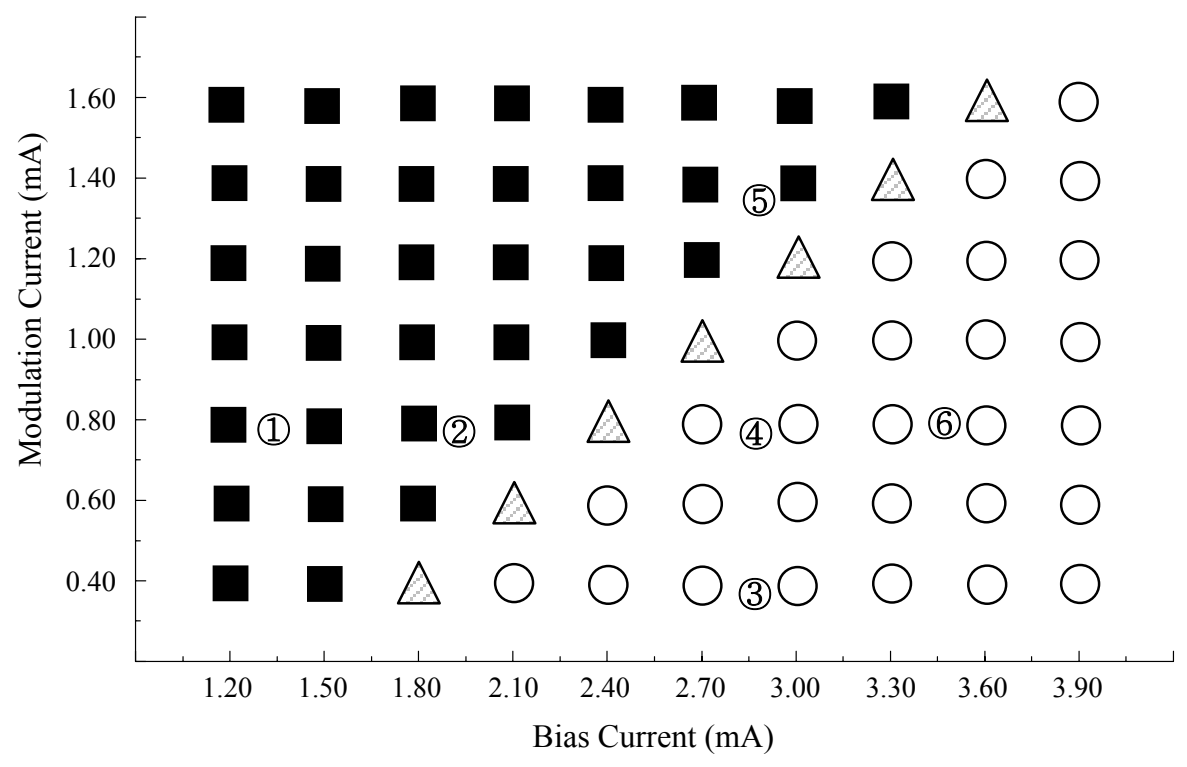

: Improper operating region

: Proper operating region

Fig. 33 Operating regions for FFPI sensor with a VCSEL. 

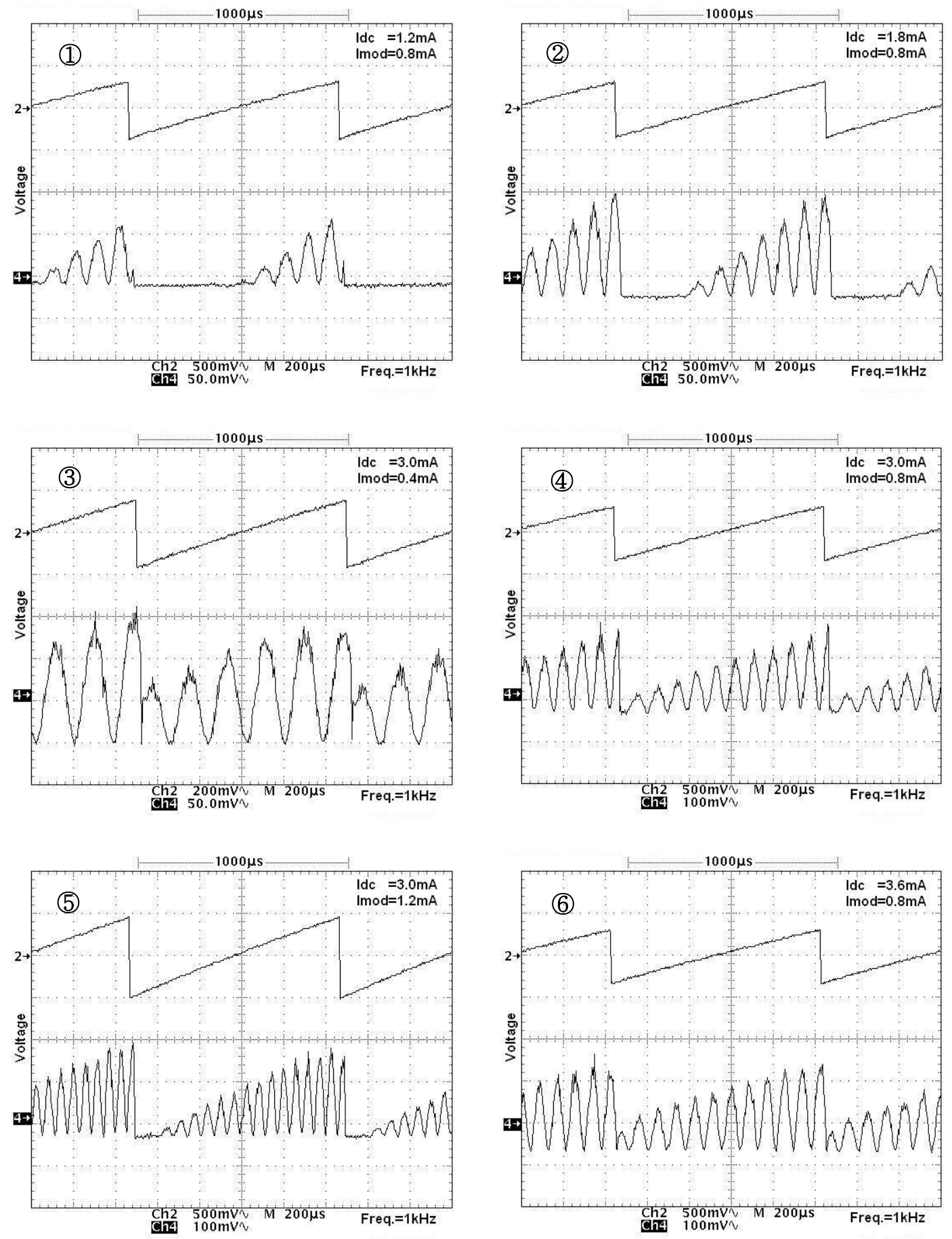

Fig. 34 The fringe pattern of FFPI sensor at each point indicated in Fig. 33. 


\section{Operation of FFPI Sensor with VCSEL at High Modulation Frequency and}

\section{Modulation Depth}

Originally the VCSEL is designed to be used for the high speed data communication. This allows the evaluation of the FFPI sensor performance at high frequencies as well. The fringe patterns of the FFPI sensor when driven with a sawtooth modulation frequency of 10, 20, 50 and $100 \mathrm{kHz}$, respectively, are shown in Fig. 35.
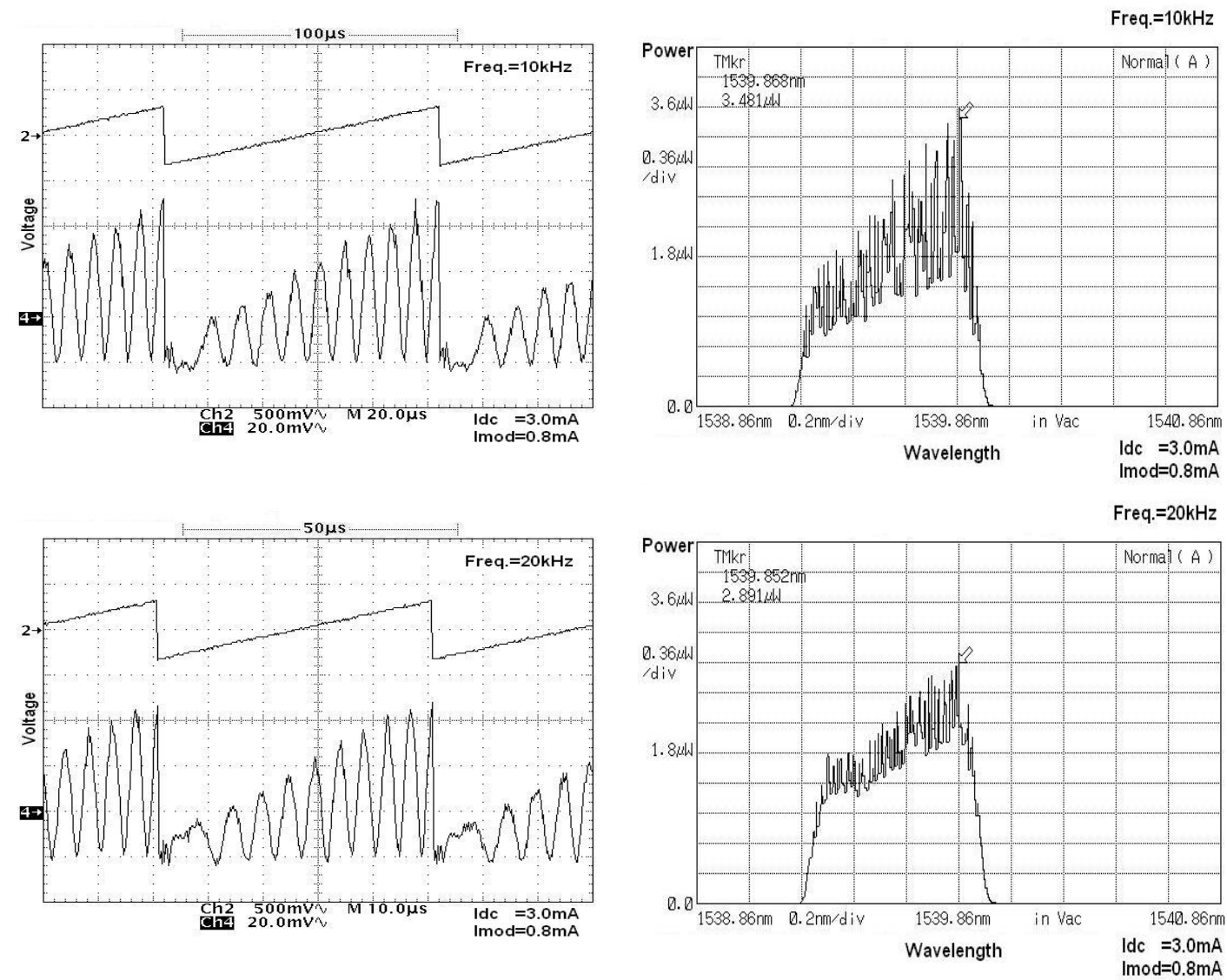

Fig. 35 Fringe pattern of FFPI sensor with VCSEL modulation frequency $10 \mathrm{kHz}, 20 \mathrm{kHz}, 50 \mathrm{kHz}$ and $100 \mathrm{kHz}$ with a horizontal scale of $20 \mu \mathrm{s} / \mathrm{div}$, $10 \mu \mathrm{s} / \mathrm{div}, 5 \mu \mathrm{s} / \mathrm{div}$ and $2 \mu \mathrm{s} / \mathrm{div}$ respectively. Bias current $3.0 \mathrm{~mA}$ and modulation current is $0.8 \mathrm{~mA}$. 
The frequency increase at a fixed bias current of $3.0 \mathrm{~mA}$ and a modulation current of $0.8 \mathrm{~mA}$, does not affect the fringe pattern and the number of fringes. As the modulation frequency increases, however, the spectrum of the VCSEL becomes multimode and it is not suitable for FFPI sensor operation.
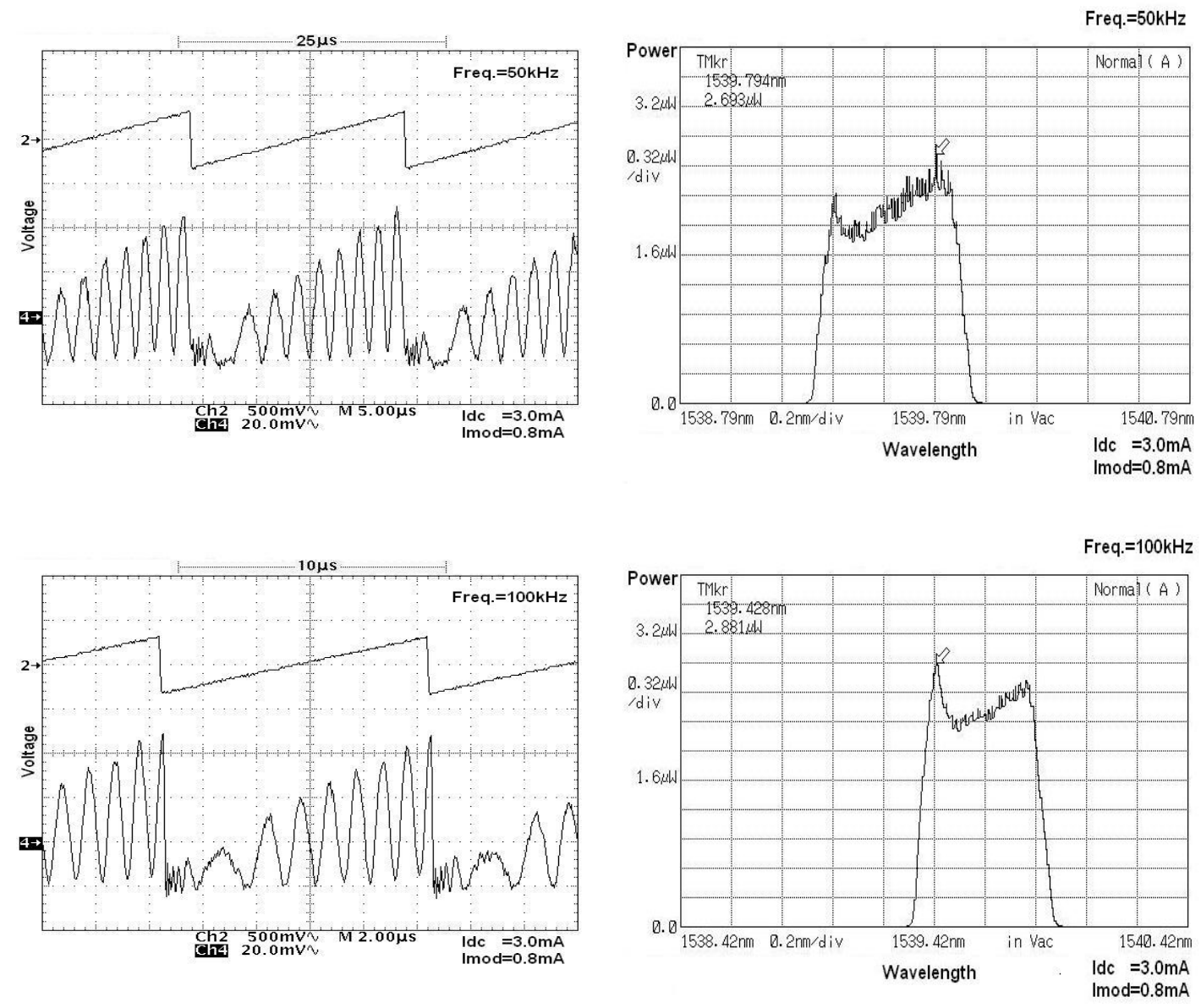

Fig. 35 Continued 


\section{Dependence of VCSEL Frequency on Drive Current}

As the VCSEL diode bias current was increased, not only the emitting power but also the peak emission wavelength of the VCSEL diode increased. The spectra of the VCSEL diode with dc bias current increase from $0.8 \mathrm{~mA}$ to $4.7 \mathrm{~mA}$ in increments of 0.4mA are shown in Fig. 36. Fig. 37 shows the spectra of the VCSEL with saw-tooth modulation, as the dc bias current was increased from $1.2 \mathrm{~mA}$ to $3.9 \mathrm{~mA}$ in increments of $0.3 \mathrm{~mA}$ at $100 \mathrm{kHz}$ frequency.

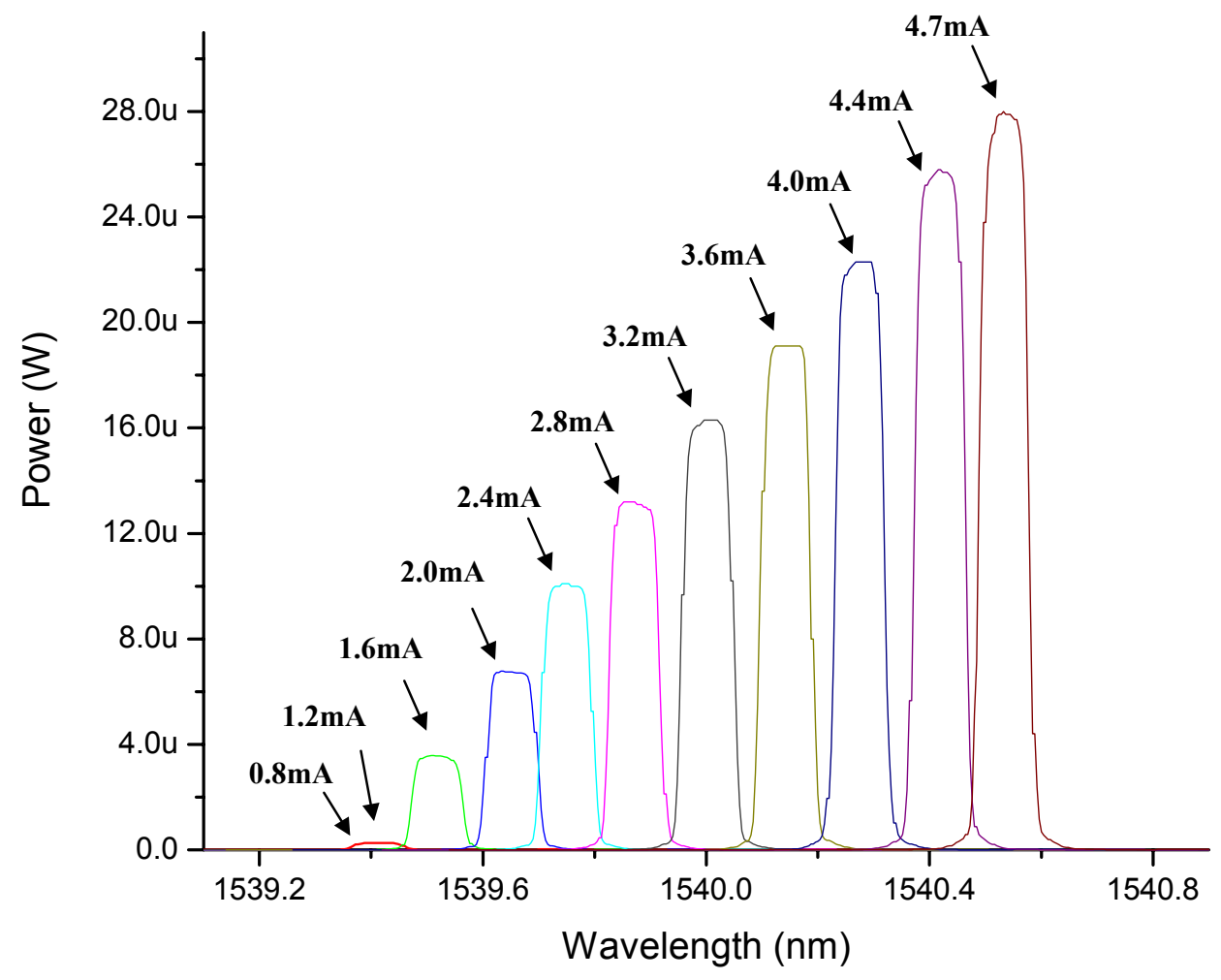

Fig. 36 Spectrum of dc biased VCL1550 VCSEL. 


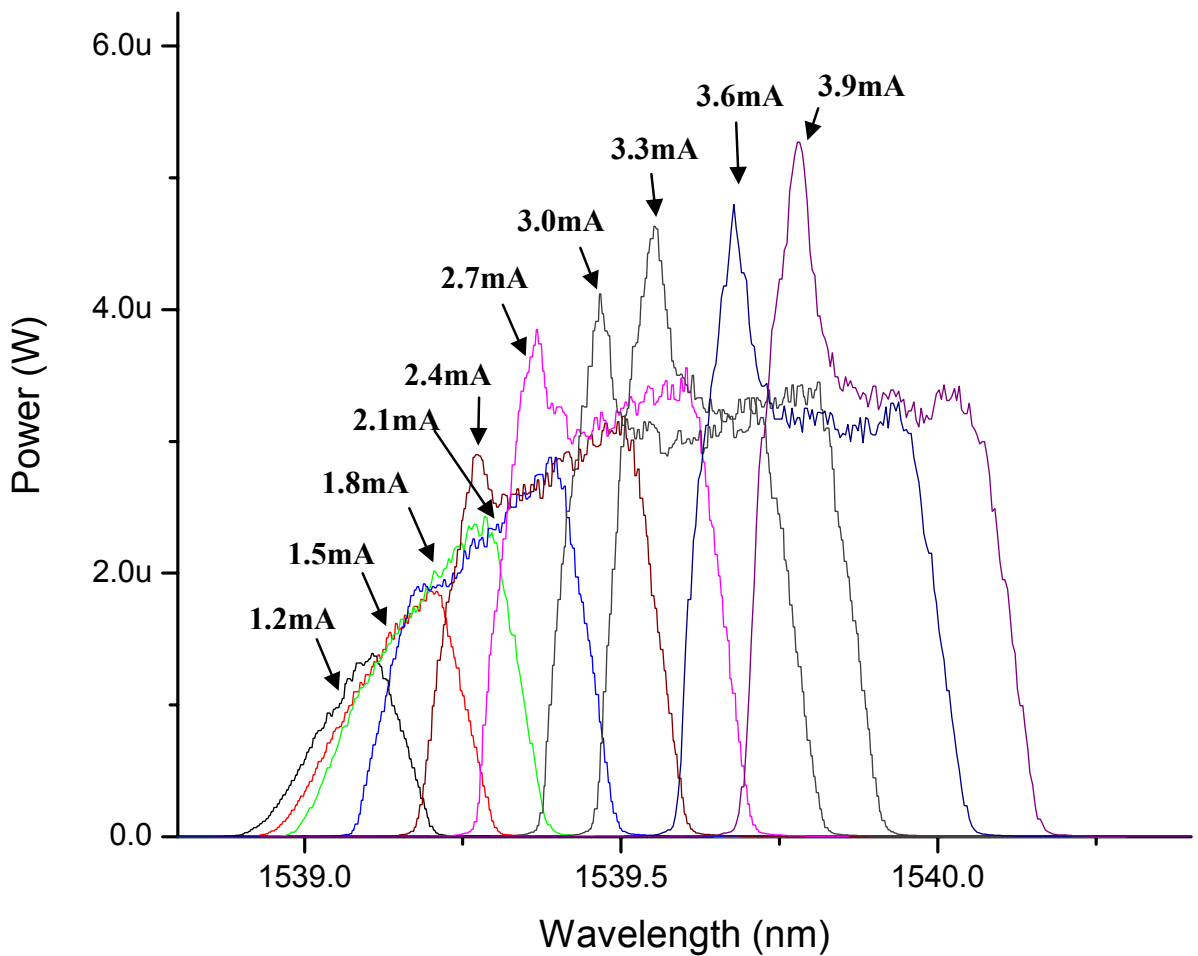

Fig. 37 Spectrum of VCL1550 VCSEL with dc bias current increase when a saw-tooth modulation current $(0.6 \mathrm{~mA})$ is applied. Modulation frequency is $100 \mathrm{kHz}$. 


\section{E. Dependence of FFPI Sensor Fringe Pattern on Temperature}

The fringe pattern variation with the increase of temperature is shown in Fig.

38. As the temperature is increased in $1{ }^{\circ} \mathrm{C}$ increments from $142^{\circ} \mathrm{C}$ to $153^{\circ} \mathrm{C}$, the fringe pattern shifts to the right as shown. To shift one complete fringe pattern, about $4^{\circ} \mathrm{C}$ is required.
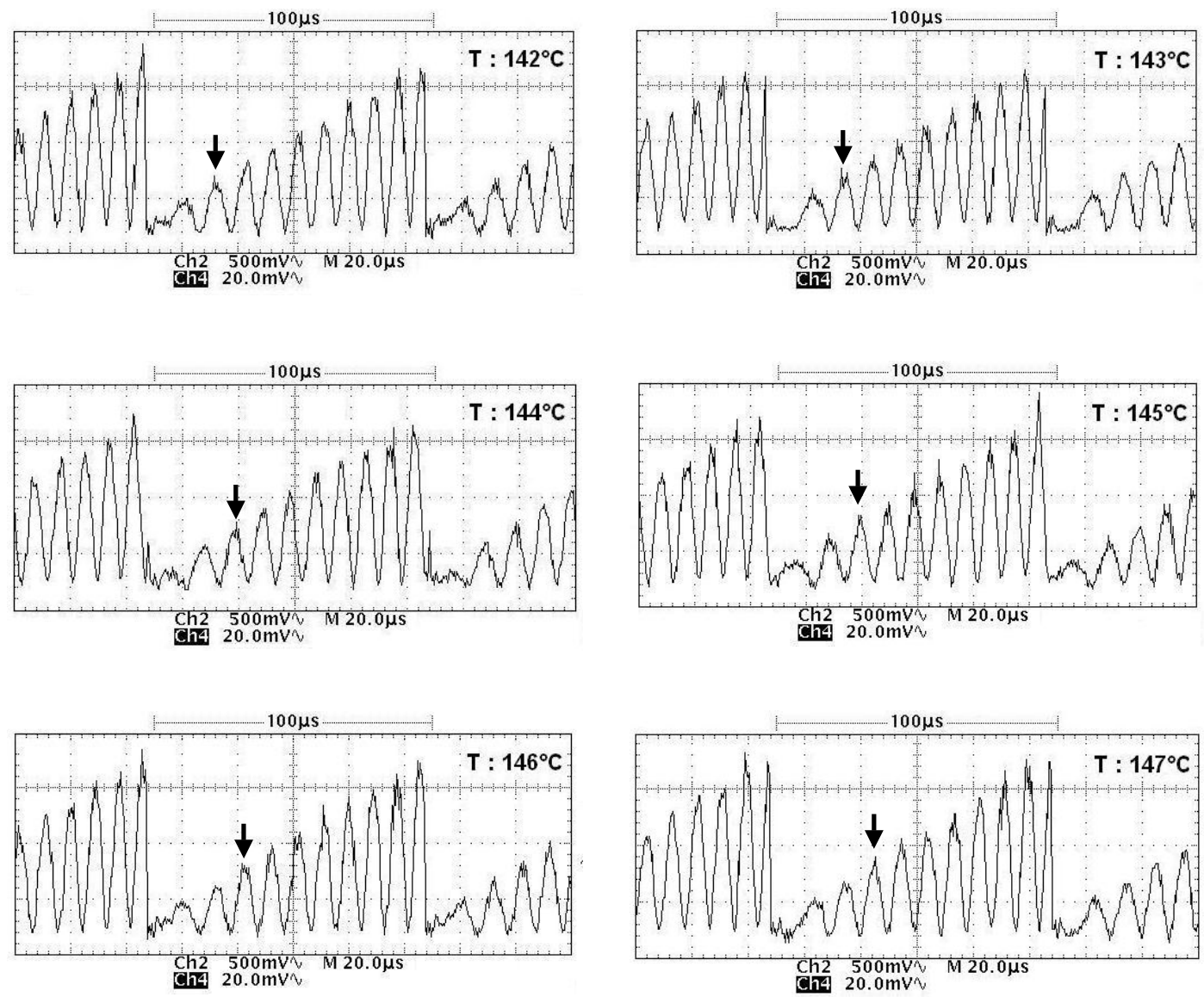

Fig. 38 Dependence of fringe pattern on temperature when the sensor is monitored with a $1550 \mathrm{~nm}$ VCSEL diode over temperature range $142^{\circ} \mathrm{C}$ to $154^{\circ} \mathrm{C}$ with $2.7 \mathrm{~mA}$ bias current and $0.8 \mathrm{~mA}$ modulation current. 

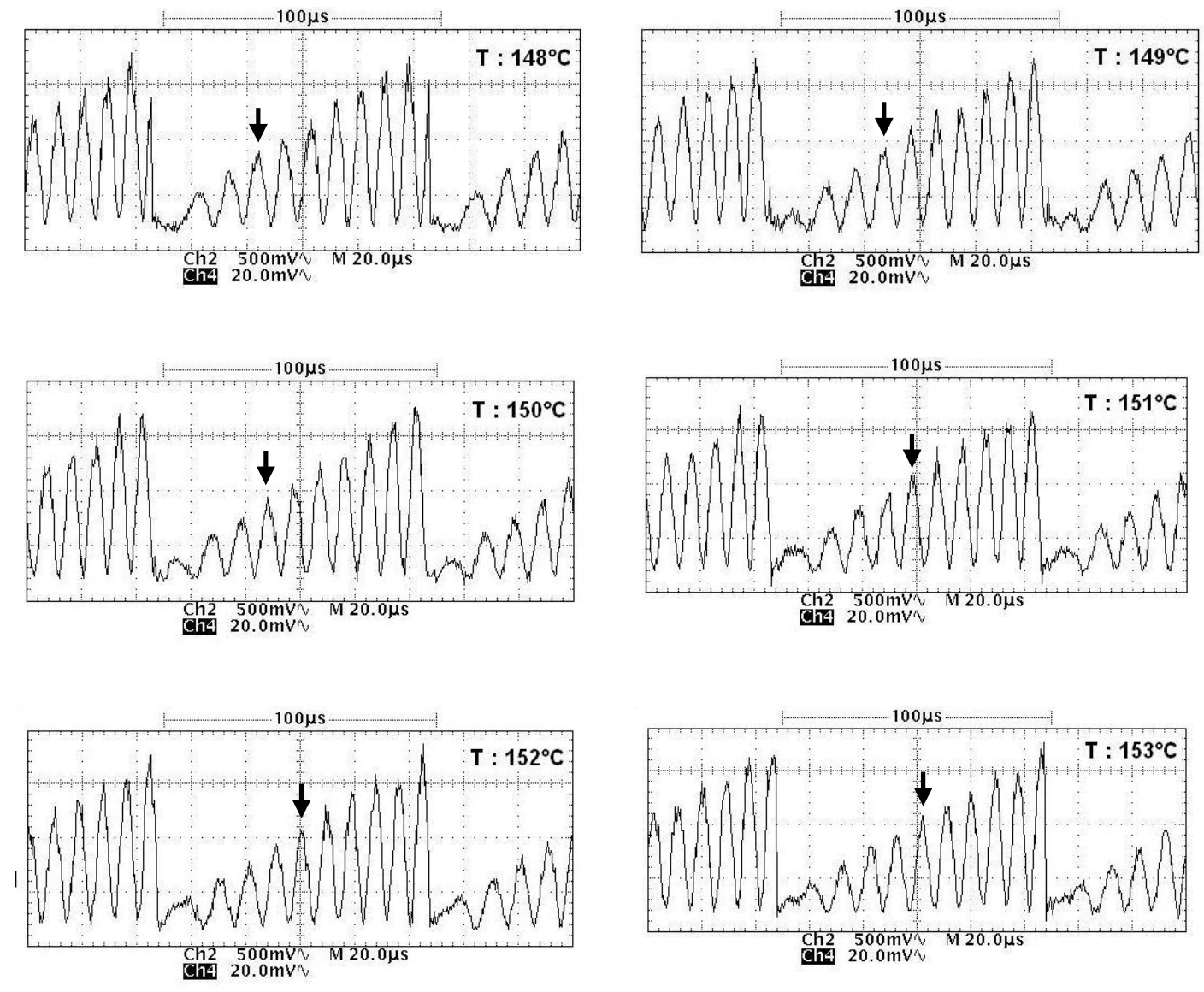

Fig 38. Continued 


\section{F. Discussion and Analysis of Results}

Various features of the VCSEL diode characteristics were observed in the experimental results of this chapter. According to the spectra of the VCSEL in Figure 36, the emitting power and peak emission wavelength increase when the bias current increases. When the dc bias current increase from $0.8 \mathrm{~mA}$ and $4.7 \mathrm{~mA}$ in increments of $0.4 \mathrm{~mA}$, the current tuning factor for this laser can be expressed as

$$
\frac{d \lambda}{d I}=0.3256 n m / m A
$$

Thus, the dependence of VCSEL frequency $v$ on current can be calculated as

$$
\frac{d v}{d I}=\frac{d \lambda}{d I} \frac{d v}{d \lambda}
$$

Using the equation $\lambda v=\mathrm{c}$, with $\mathrm{c}$ the speed of light in free-space, it follows that

$$
v=\frac{c}{\lambda}, d v=-\frac{c}{\lambda^{2}} d \lambda
$$

or

$$
\frac{d v}{d \lambda}=-\frac{c}{\lambda^{2}}
$$

Substituting eq. (15) into eq. (13), gives

$$
\frac{d v}{d I}=-\frac{c}{\lambda^{2}} \frac{d \lambda}{d I}
$$

from eqs. (12) and (16), it then follows that 


$$
\frac{d v}{d I}=-41.2 G H z / m A
$$

where $\mathrm{c}=3.00 \times 10^{8} \mathrm{~m} / \mathrm{s}$ and $\lambda=1539.97 \mathrm{~nm}$ are used.

The temperature increase responsible for tuning the laser can also be estimated.

From the expression

$$
\frac{d v}{d T}=\frac{d \lambda}{d T} \frac{d v}{d \lambda}
$$

Substituting eq. (15) gives

$$
\frac{d v}{d T}=-\frac{c}{\lambda^{2}} \frac{d \lambda}{d T}
$$

Using the value of the wavelength temperature coefficient supplied in the data sheet of the VCSEL manufacturer

$$
\frac{d \lambda}{d T}=0.11 \mathrm{~nm} /{ }^{\circ} \mathrm{C}
$$

reduces eq. (19) to

$$
\frac{\mathrm{d} v}{\mathrm{dT}}=-13.92 \mathrm{GHz} /{ }^{\circ} \mathrm{C}
$$

From equations (17) and (21) it then follows that

$$
\frac{\mathrm{dT}}{\mathrm{dI}}=2.9597^{\circ} \mathrm{C} / \mathrm{mA} \text {. }
$$


The dependence of the optical path length of the FFPI cavity $\mathrm{nL}$ on temperature $\mathrm{T}$ can be determined from eq. (3), by expressing it as

$$
\frac{\mathrm{d} \phi}{\mathrm{dT}}=\frac{\phi}{\mathrm{nL}} \frac{\mathrm{d}(\mathrm{nL})}{\mathrm{dT}}
$$

Using the parameters $\mathrm{n}=1.458, \mathrm{~L}=12 \mathrm{~mm}$ and at $\lambda=1540 \mathrm{~nm}$ in eq. (3), the value of $\phi$ is calculated as

$$
\phi=2.2723 \times 10^{4} \times 2 \pi \quad \mathrm{rad}
$$

Since (from the experimental results in section $\mathrm{E}$ ), a $4^{\circ} \mathrm{C}$ change in temperature produces one fringe shift, and a one fringe shift corresponds to a phase change of $2 \pi$ radian, then

$$
\frac{d \phi}{d T}=\frac{2 \pi}{4^{\circ} \mathrm{C}}
$$

Substituting equations (24) and (25) into equation (23), gives the value of the temperature tuning coefficient for the optical path length of the interferometer is

$$
\frac{1}{n L} \frac{d(n L)}{d T}=11 \times 10^{-6} /{ }^{\circ} \mathrm{C}
$$




\section{CHAPTER VI}

\section{CONCLUSIONS}

The purpose of this research is to investigate the practical measurement of pressure in automotive engines which opens the way for a new technology in the immediate future. The feasibility of in-cylinder pressure measurement with a sparkplug-mounted fiber FFPI pressure optic sensor has been demonstrated.

The FFPI consists of a single mode fiber containing two internal mirrors separated by $12 \mathrm{~mm}$ cavity length. The end of the fiber is coated with $\mathrm{TiO}_{2}$ layer by magnetron sputtering, and the $\mathrm{TiO}_{2}$ coated fiber is connected to a normal fiber by splice fusing to produce internal mirrors. A gold coating and copper electroplating process were employed for protecting the sensing element from the severe environmental condition of the engine. The gold coating was accomplished by soaking FFPI element in liquid gold solution then curing by firing around $400^{\circ} \mathrm{C}$. The gold-coated fiber was then electroplated with copper. Ultimately, the gold-coated and copper-electroplated fiber sensor was buried in the metal casing of a spark plug.

To investigate the performance of the fiber sensor, field tests were conducted. A 3-cylinder automotive engine (Geo Metro) was used to monitor the in-cylinder pressure. The spark-plug-mounted fiber optic pressure sensor was installed in one of the cylinders along with a commercial piezoelectric pressure sensor in the same cylinder and used as pressure reference. The spark-plug-mounted fiber optic sensor allows measuring in-cylinder pressure without modifying the engine or disturbing 
engine ignition. Generally good agreement between pressure measured by the spark plug embedded sensors and the piezoelectric sensor was observed.

The use of a 1550nm Vertical Cavity Surface Emitting Laser (VCSEL) diode as a light source was investigated.

The light from the VCSEL diode was focused into the fiber with angle polished fiber ends and anti-reflection coated lens. To avoid back reflection, instead of using an isolator the coupling lens was slightly tilted.

To find a good fringe pattern for the FFPI sensor, the combination of bias current, modulation current and modulation frequency were investigated over a range of dc bias currents from $1.2 \mathrm{~mA}$ to $3.9 \mathrm{~mA}$ and peak-to-peak modulation current amplitudes from $0.4 \mathrm{~mA}$ to $1.4 \mathrm{~mA}$.

A laser tuning of $-41.2 \mathrm{GHz} / \mathrm{mA}$ was determined from measurements of the shift in the spectral peak of the laser output as a function of dc bias current. Using the value of the wavelength temperature coefficient supplied by the manufacturer and the measured spectral tuning, the temperature change was determined to be $2.9597^{\circ} \mathrm{C} / \mathrm{mA}$.

In temperature tests of the FFPI sensor, the fringe pattern shifts linearly by one fringe for every $4^{\circ} \mathrm{C}$ change in temperature. From this data, the temperature tuning coefficient for the optical path length was determined to be $11 \times 10^{-6}{ }^{\circ} \mathrm{C}$. The use of a VCSEL diode as a light source, offers a cost effective alternative to DFB laser diode, and can be used without inserting isolators. 


\section{CHAPTER VII}

\section{RECOMMENDATIONS}

The most outstanding feature of FFPI sensor lies in its simple manufacturing method at relatively low cost. Yet, every FFPI sensor needs to be manufactured and optimized individually. A standard fabrication procedure of an internal mirror needs to be generalized for more reliable and batch manufacturing. An automatic process for cleaving and alignment during splicing is also recommended.

Potentially, spark-plug-mounted FFPI sensors may be applied to automobile engine control systems for reducing emissions and improving fuel economy. The optical pressure sensing system requires a stable environment. Thus, their implementation inside vehicles in motion needs to be addressed. In addition, the signal conditioning unit should be investigated for higher sampling rate and smaller size

More investigations are needed for the use of VCSEL diode. Specifically, the response of a VCSEL diode based sensor system to variations in temperature, pressure and strain need to be examined. 


\section{REFERENCES}

[1] L. Lundqvist, K.Button, P. Nijkamp, The Automobile, Northampton, MA : Edward Elgar Publishing, Inc., pp. 122-122, 2003.

[2] J.D. Powell, "Engine control using cylinder pressure: past, present, and future," Journal of Dynamic Systems, Measurement, and Control, vol. 115, pp. 343-350, June 1993.

[3] C.E Lee and H. F. Taylor, "Interferometric optical fiber sensors using internal mirror," Electronic Letters, vol. 24, pp. 193-194, Feb.18,1988.

[4] R.A. Atkins, J.H. Gardner, W.N. Gibler, C.E. Lee, M.D. Oakland, M.O. Spears, V.P. Swenson, H.F. Taylor, J.J. McCoy, and G. Beshouri, "Fiber-optic pressure sensors for internal combustion engines," Applied Optics, vol. 33, no 7, pp. 1315-1320, Mar. 1, 1994.

[5] C.E. Lee, W.N. Gibler, R.A. Atkins, J.J. Alcoz and H.F. Taylor, "Metal-embedded fiber-optic Fabry-Perot sensors," Optic Letters, vol. 16, pp. 1990-1992, 1991.

[6] T. Bae, "Spark-plug-mounted fiber optic sensor for measuring in-cylinder pressure in engines,” M.S. thesis, Texas A\&M University, College Station, 2001.

[7] T.Bae, R.A. Atkins, and H.F. Taylor, Texas A\&M University, College Station, TX, and W.N Gilber, Fiber Dynamics, Inc., Bryan, TX, “An interferometric fiber optic sensor embedded in a spark plug for in-cylinder pressure measurement in engines", Optical Fiber Sensor Conference paper, May 2002, pp. 419-42. 
[8] T. Bae, R. A. Atkins, H. F. Taylor, and W. N. Gibler, "Interferometric fiber-optic sensor embedded in a spark plug for in-cylinder pressure measurement in engines," Applied Optics, Vol. 42, pp. 1003-1007, February 2003.

[9] H.S Choi, "Fiber optic Fabry-Perot engine pressure sensor system using a continuous wave laser source," M.S. thesis, Texas A\&M University, College Station, 1994.

[10] C.E. Lee, R.A. Atkins and H.F. Taylor, "Performance of a fiber-optic temperature sensor from -200 to $1050{ }^{\circ} \mathrm{C}$, " Optic Letters, vol. 13, pp. 1038-1040, November 1998. [11] Wilmsen, Temkin, and A. Coldren, Vertical-Cavity Surface-Emitting Lasers, Cambridge, UK : Cambridge University Press, 1999.

[12] K. Lee, "Fiber Fabry-Perot interferometer (FFPI) sensor using vertical cavity surface emitting laser (VCSEL)," Ph.D. dissertation, Texas A\&M University, College Station, 2005.

[13] C.E Lee, "Internal mirror technique for fiber optic application," Ph.D. dissertation, Texas A\&M University, College Station, 1988.

[14] J.S Lee, "Fiber optic hydrophone sensor arrays using low reflectance internal mirrors,” M.S. thesis, Texas A\&M University, College Station, 1998.

[15] E. Manahan, General Applied Chemistry, $2^{\text {nd }}$ Ed. Boston, MA : Willard Grant Press, 1978.

[16] E. Mortimer, Introduction to Chemistry, New York : D.Van Nostrand Company, 1977. 
APPENDIX A

\section{Laser Diode Drive Circuit}

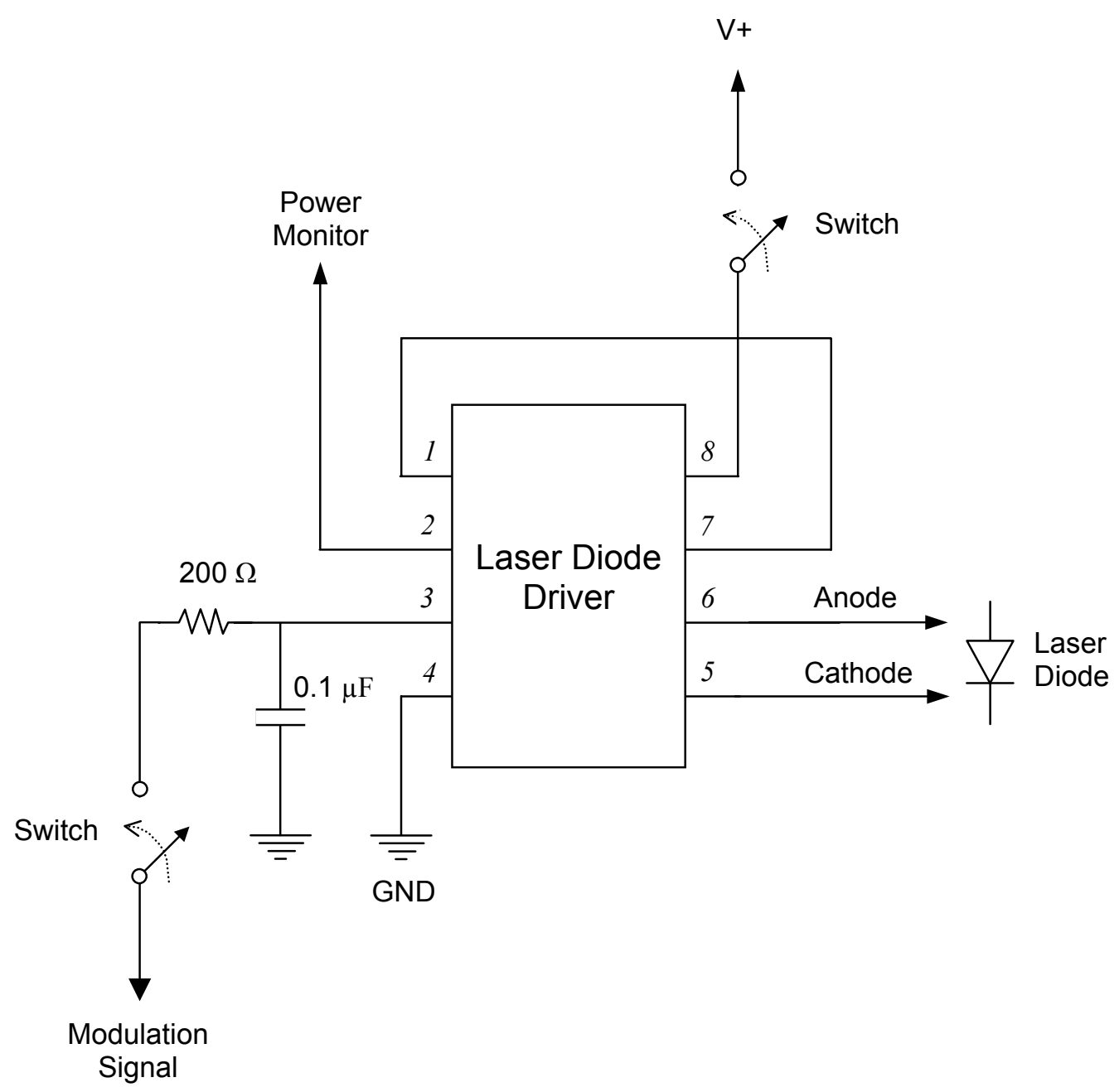




\section{APPENDIX B}

\section{VCSEL Laser Driving Circuit}

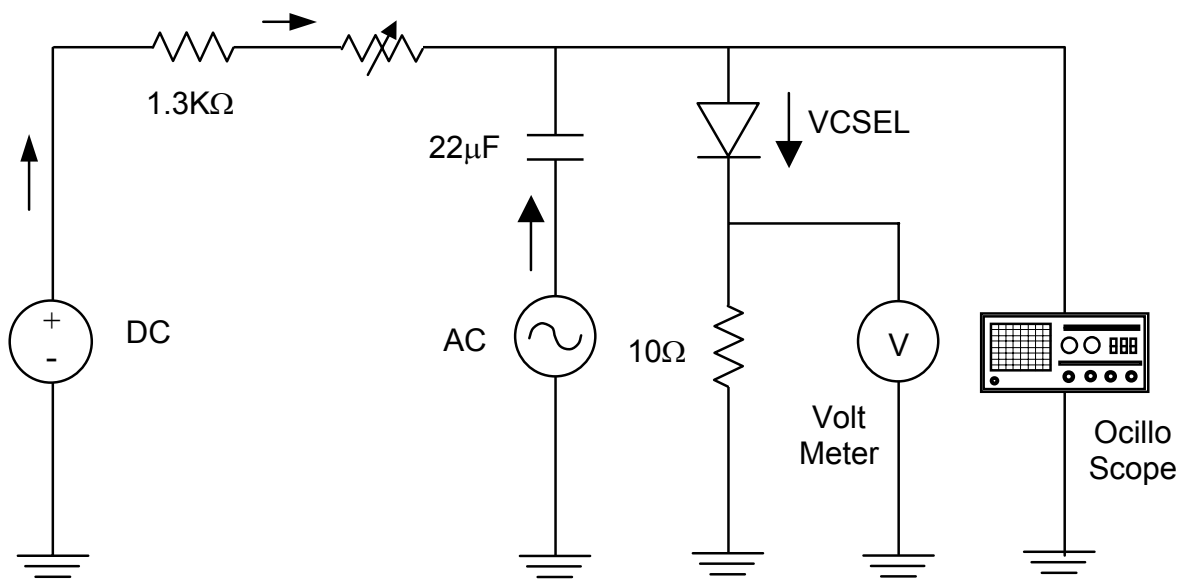




\section{VITA}

Mr. Taehan Bae was born in Seoul, Korea on January 4, 1971. He received the degree of Bachelor of Science in electrical engineering at the University of Seoul in Seoul, Korea in February 1996. During the period of March, 1992 to September, 1993, he served in the Korean Army. From January, 1996 to January, 1997, he worked in the technical sale department at LG Industrial Co., Ltd. of Korea. He received the Master of Science degree in electrical engineering from Texas A\&M University, College Station in December 2001.

He began his $\mathrm{Ph} . \mathrm{D}$. degree in electrical engineering at Texas A\&M University in the spring of 2002. He has been working as a Research Assistant from January of 2000. His main interest of studies is in fiber optic sensors, optical communication, optical filters and fiber to the home (FTTH). He is married to Jihyun Park.

Mailing Address : 4-8, 999, Kilum3-Dong, Seoungbook-Gu

Seoul, 136-113, Rep. Of Korea.

baeth@ece.tamu.edu 